\title{
Incluindo Funcionalidades no Modelo BRAMS para Simular o Transporte de Cinzas Vulcânicas: Descrição e Análise de Sensibilidade Aplicada ao Evento Eruptivo do Puyehue em 2011
}

\author{
Claudio Augusto Borges Pavani ${ }^{1}$, Saulo Ribeiro de Freitas ${ }^{2}$, Wagner Flauber Araujo Lima ${ }^{1}$, \\ Simone Marilene Sievert da Costa Coelho ${ }^{1}$, Nilton Manuel Évora do Rosário ${ }^{3}$, \\ Demerval Soares Moreira ${ }^{4}$, Marcos Cezar Yoshida ${ }^{1}$ \\ ${ }^{1}$ Centro de Previsão do Tempo e Estudos Climáticos, Instituto Nacional de Pesquisas Espaciais, \\ Cachoeira Paulista, SP, Brasil. \\ ${ }^{2}$ Goddard Space Flight Center, National Aeronautics and Space Administration, Greenbelt, \\ Marylang, Estados Unidos. \\ ${ }^{3}$ Universidade Federal de São Paulo, São José dos Campos, SP, Brasil. \\ ${ }^{4}$ Universidade Estadual Paulista "Júlio de Mesquita Filho”, Bauru, SP, Brasil.
}

Recebido: 25/11/2014 - Aceito: 19/11/2015

\begin{abstract}
Resumo
Este trabalho possui dois objetivos principais, o primeiro é apresentar uma descrição de como o modelo atmosférico BRAMS foi estruturado com o intuito de capacitá-lo a simular a emissão, dispersão e sedimentação de cinzas vulcânicas; o segundo é fazer uma análise de sensibilidade com relação a diversas configurações do modelo, com o intuito de obter uma configuração adequada para prever a concentração de cinzas vulcânicas após eventos eruptivos. Avaliando os resultados do modelo com dados observados, principalmente com relação ao satélite CALIPSO, concluiu-se que o modelo BRAMS foi capaz de simular e prever com relativa precisão a posição e concentração das cinzas vulcânicas na atmosfera.
\end{abstract}

Palavras chave: modelagem numérica, dispersão de poluentes, vulcões, análise de sensibilidade, métodos numéricos de advecção, cinzas vulcânicas.

\section{Including Functionalities in BRAMS Model to Simulate the Volcanic Ash Transport: Description and Sensitivity Analysis Applied to the Eruptive Event of Puyehue in 2011}

\begin{abstract}
This work has two main goals, the first is provide a description of how the atmospheric BRAMS model was structured in order to enable it to simulate the emission, dispersion and sedimentation of volcanic ash; the second is do a sensitivity analysis, with respect to several configurations of the model, in order to obtain an optimized configuration for predict the volcanic ash concentration after eruptive events. Comparing model results with observed data, mostly related with CALIPSO satellite, we concluded that the BRAMS model was able to simulate and forecast with relative accuracy the location, sedimentation and concentration of volcanic ash in the atmosphere.
\end{abstract}

Keywords: numerical modeling, dispersion of pollutants, volcanoes, sensitivity analysis, numerical methods of advection, volcanic ash.

Autor de correspondência: Claudio Augusto Borges Pavani, claudio.pavani@gmail.com. 


\section{Introdução}

A modelagem numérica do transporte de cinzas e gases emitidos por erupções vulcânicas possui grande importância para a meteorologia e ciências atmosféricas, pois estes contaminantes geram impactos no tempo e clima, além de poluírem o ar, o solo e a água. Os vulcões afetam o tempo e o clima, pois liberam gases que acentuam o efeito estufa como água e dióxido de carbono; e também liberam cinzas vulcânicas e enxofre, os quais causam efeito de resfriamento. $\mathrm{O}$ enxofre em contato com moléculas de água se transforma em aerossol de acido sulfúrico, este aerossol assim como as cinzas vulcânicas retroespalham a radiação solar de volta ao espaço. $\mathrm{O}$ efeito de resfriamento gerado por estes aerossóis predomina sobre o efeito de aquecimento associado à absorção de ondas curtas e emissão de ondas longas (San Diego State University, 2012), tanto que em grandes erupções do passado são responsáveis por decréscimo da temperatura global (USGS, 2014). Contudo, em escalas de tempo suficientemente longas, o efeito do aquecimento associado aos gases de efeito estufa emitidos tende a predominar sobre o efeito de resfriamento. Isto se justifica pelo fato de que os aerossóis sedimentam rapidamente em relação aos gases, e são removidos por processos úmidos com eficiência muito maior em relação aos mesmos, fazendo com que o tempo de vida dos aerossóis na atmosfera seja muito menor.

A modelagem do transporte e das emissões vulcânicas também tem importância econômica, pois os gases e cinzas liberados pela erupção causam danos em diversas estruturas de engenharia devido à chuva ácida; também causam danos à agricultura, à pecuária, à aviação, à saúde e ao meio ambiente (USGS, 2012b). Pelo fato das cinzas serem corrosivas estas causam danos internos e externos a diversos componentes dos aviões, os quais resultam em elevados custos de manutenção e riscos de acidentes. Em particular, as cinzas podem até mesmo causar falha dos motores de uma aeronave (Mendonça, 2011). Os danos à agricultura são causados principalmente devido ao soterramento das plantas pelas cinzas e contaminação do solo, e os danos à pecuária devido a ingestão de cinzas por parte dos animais, pois as cinzas possuem elevados teores de flúor, o qual quando ingerido em alta concentração, prejudica a saúde do animal ao ponto de levá-lo a morte (USGS, 2012c).

Eventos eruptivos não são raros no mundo, pois existem cerca de 550 vulcões e destes, em média, 20 estão em atividade em algum lugar sobre o planeta (Smithsonian Institute, 2012a). Em particular, no dia 04 de junho de 2011 por volta das 20:15 UTC o vulcão Puyehue, que se localiza no Complexo Vulcânico Puyehue-Cordón Caulle (CCVC), na "Región de los Rios" no Chile, entrou em erupção. Os produtos desta erupção alcançaram inicialmente uma altitude da ordem de $12 \mathrm{~km}$ acima do nível médio do mar e chegaram até ao sul do Brasil. A região que se encontra o vulcão é dominada predominantemente pelos ventos de oeste, sobre esta região em altas altitudes ocorrem os jatos polar e subtropical. Estes jatos contribuíram para o rápido deslocamento das cinzas ejetadas, sendo transportadas a longas distâncias, permitindo darem a volta no mundo em poucos dias, atingindo a Austrália e retornando ao sul da América do Sul, como mostrado na Fig. 1. Esta figura mostra uma imagem do sensor OMI a bordo do satélite AURA que detecta a densidade de partículas na coluna atmosférica (NASA, 2012).

Neste estudo foi acrescentado processos relacionados à emissão vulcânica ao módulo de química do modelo $\mathrm{Bra}$ zilian develoments on the Regional Atmospheric Modeling System (BRAMS) que se encontra em sua $5^{\text {a }}$ versão (Freitas et al., 2009a: Longo et al., 2013). Com este trabalho o BRAMS inclui capacidade de simular a emissão, o transporte, a dispersão e a sedimentação das cinzas vulcânicas, assim como alguns gases associados a eventos eruptivos (presentemente, $\mathrm{CO}_{2}, \mathrm{CO}$ e $\mathrm{SO}_{2}$ ).

Na modelagem da emissão de cinzas vulcânicas, estas são distribuídas acima do vulcão segundo a altura de injeção da erupção. A quantidade de cinzas emitida pelo vulcão está correlacionada com a altura de injeção, tal processo é o mais comum na modelagem de cinzas vulcânicas; este processo é utilizado como por exemplo pelos modelos FLEXPART (http://flexpart.eu) e NAME (Kristiansen et $a l ., 2012)$. Esta distribuição vertical das cinzas emitidas não interage com à atmosfera, negligenciando fatores que podem influenciar na ascensão das cinzas, como por exemplo a umidade específica do ar e quantidade de água no magma, que contribuem positivamente para a ascensão das cinzas, através liberação de calor latente, outro exemplo é a velocidade horizontal do vento que contribui para o aumento do entranhamento de ar mais frio no material ejetado, diminuindo assim a altura de injeção. A correlação entre altura de injeção e velocidade horizontal do vento foi estudada no artigo do Bursik (2009) utilizando os modelos numéricos ATHAM e BENT.

Neste trabalho, a altura de injeção das cinzas vulcânicas é obtida através de dados observados pelo Observatorio Volcanológico de los Andes del Sur (OVDAS) (OVDAS, 2012) e Smithsonian Institution (SI) (SI, 2012b). Dados observados sobre a dispersão e sedimentação das cinzas, embora bastante escassos, foram utilizados para comparar com os resultados do modelo. Foram produzidos análises de sensibilidade, com o intuito de encontrar a melhor configuração do modelo para simular a dispersão e sedimentação das cinzas vulcânicas.

\section{Material e Métodos}

Esta seção é dividida em quatro partes, a primeira trata dos dados observados sobre o evento eruptivo, a segunda é uma descrição básica do modelo atmosférico utilizado, a terceira se refere à estruturação do BRAMS com o intuito de capacitá-lo a modelar o transporte e sedimen- 


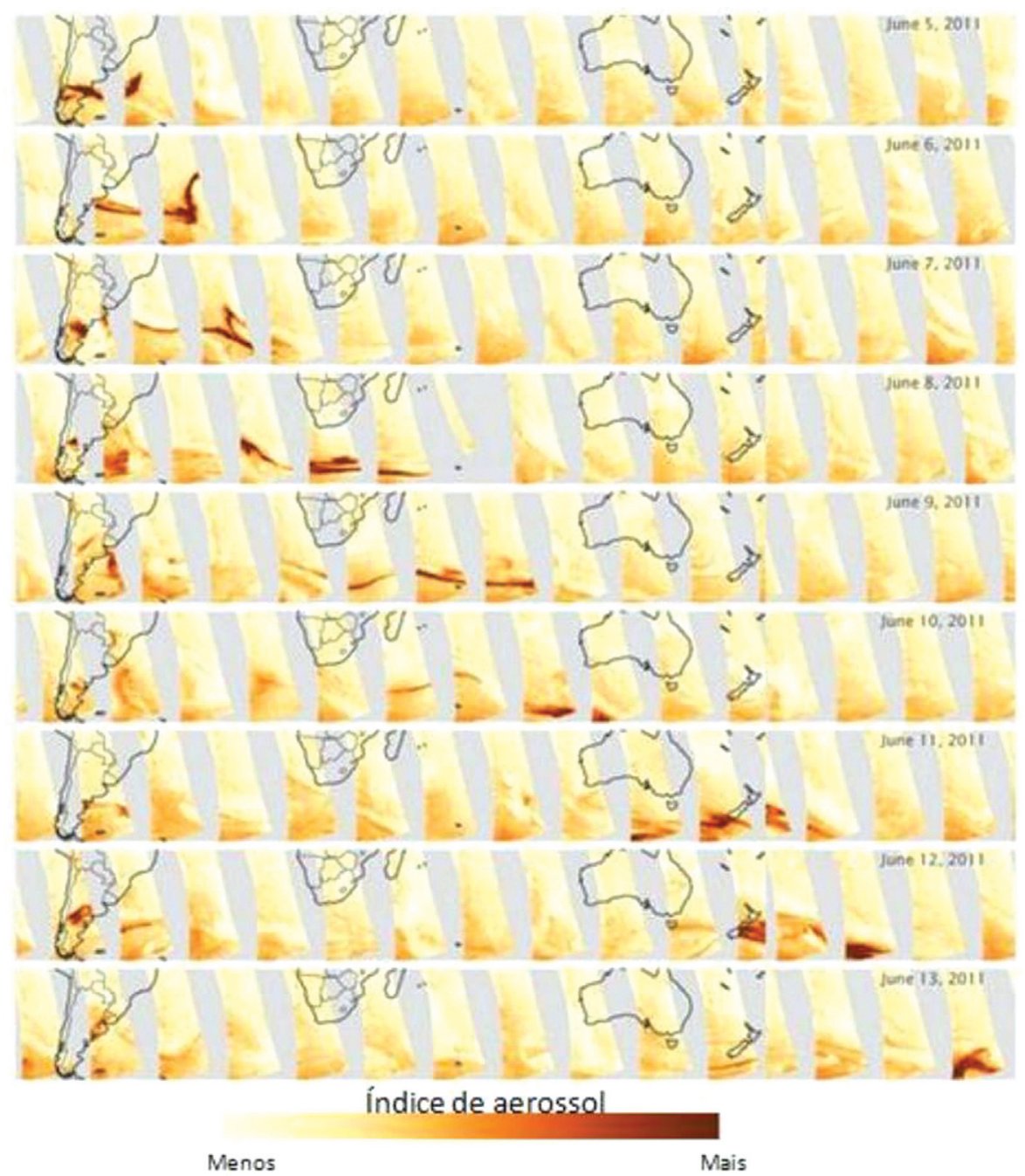

Figura 1 - Índice de aerossol atmosférico denotando a qualitativamente a posição da pluma de cinzas associada a erupção do vulcão Puyehue. A série começa em 05/06/2011, um dia após o inicio da atividade eruptiva, e vai até o dia 13 do mesmo mês. Fonte:Adaptado da NASA, Disponível em: http://earthobservatory.nasa.gov/NaturalHazards/view.php?id=51057. Acessado em 25 de Novembro de 2014.

tação de cinzas vulcânicas, e a quarta parte descreve a análise de sensibilidade.

\subsection{Dados observacionais}

O OVDAS produziu relatórios diários descrevendo as atividades eruptivas do vulcão Puyehue, e o SI produziu relatórios semanais desde o início das atividades eruptivas. Os relatórios do OVDAS fornecem informações sismológicas, além de dados de altura de injeção e direção da dispersão da pluma vulcânica. A altura de injeção da emissão vulcânica é o único dado observacional de entrada no modelo relativo à atividade vulcânica. Pelo fato dos dados sísmicos serem de fácil obtenção, buscou-se correlacionar dados sísmicos oferecidos pelo OVDAS com a altura de injeção. Porém, nenhuma correlação foi observada; caso houvesse seria de grande valia para modelagem da dispersão de cinzas vulcânicas, pois devido às condições meteorológicas ou a posição dos sensores, nem sempre é possível determinar a altura de injeção das cinzas vulcânicas. A altura de injeção fornecida pelo OVDAS é estimada através da triangulação de câmeras colocadas próximas a abertura vulcânica, estas câmeras detectam no espectro do visível.

Através de um produto desenvolvido pela DSA (Divisão de Satélites Ambientais) do CPTEC/INPE, o qual consegue detectar cinzas vulcânicas utilizando dados do sensor SEVIRI (Spinning Enhanced Visible and Infrared Imager) a bordo do satélite Meteosat-8 (Costa, 2011 e Costa et al., 2012), foi possível estimar com relativa acurácia a posição horizontal das cinzas vulcânicas. Este produto avalia a diferença entre a temperatura de brilho (TB) do comprimento de onda $10.8 \mu \mathrm{m}$ (IR10) e $12 \mu \mathrm{m}$ (IR12). Na presença de cinzas vulcânicas a diferença da TB torna-se negativa, quanto mais negativa maior a quantidade de cinzas detectadas. O sensor SEVIRI captura e disponibiliza imagens a cada $15 \mathrm{~min}$. 
Também foram utilizados dados do sensor CALIOP (Cloud-Aerosol Lidar with Orthogonal Polarization) a bordo do satélite CALIPSO (Cloud-Aerosol Lidar and Infrared Pathfinder Satellite Observations) devido a sua maior precisão espacial e temporal na detecção de partículas suspensas na coluna atmosférica.

\subsection{O desenvolvimento do módulo de cinzas vulcânicas no modelo BRAMS}

O modelo BRAMS é um modelo regional atmosférico euleriano, no qual está acoplado o modelo de química e aerossóis denominado Coupled Chemistry-AerosolTracer Transport model (CCATT) (Longo et al., 2013). O acoplamento entre os componentes atmosférico e de química-aerossóis é do tipo 'online' com as equações sendo resolvidas utilizando o mesmo sistema de coordenadas, mesmo passo de integração temporal, mesmo esquema de transporte e de parametrizações físicas (veja Grell and Baklanov (2011) para uma recente revisão dos tipos de acoplamentos e os benefícios de acoplamentos on-line). Detalhes da forma de resolver a equação da continuidade aplicada a gases reativos e aerossóis podem ser encontrados em Freitas et al. (2009b) e Longo et al. (2013).

Um elemento essencial na simulação do transporte de particulados é sua velocidade terminal, pois devido ao seu peso, estes não se movem verticalmente com a mesma velocidade que as parcelas de ar na qual se encontram, mas possuem uma velocidade de queda, conhecida como velocidade terminal que depende das propriedades físicas da partícula e da aceleração gravitacional. A velocidade terminal $\left(V_{\text {fall }}\right)$ de uma partícula considerando uma atmosfera em repouso é dada pela Eq. (1) (Pruppacher, 1997).

$$
V_{\text {fall }}=\frac{2 r^{2}\left(\rho_{\text {part }}-\rho_{a r}\right) g G_{i}}{9 n_{a r}}
$$

onde $(r)$ é o raio das partículas, $\left(\rho_{\text {part }}\right)$ e $\left(\rho_{a r}\right)$ são as densidades das partículas e do ar respectivamente, $(g)$ é aceleração da gravidade, $\left(n_{a r}\right)$ é a viscosidade dinâmica do ar (dependente da temperatura) e $\left(G_{i}\right)$ é um fator para corrigir os desvios do regime de Stokes, no qual o raio da partícula é muito maior que o caminho livre médio do ar (distância média percorrida por uma partícula até que esta se colida com outra partícula). Desta forma, quando partículas estão imersas em um fluido que possui velocidade vertical não nula, sua velocidade vertical efetiva $\left(w_{e f}\right)$ se dá por

$$
W_{e f}=W_{a r}-V_{\text {fall }}
$$

em que $\left(w_{a r}\right)$ é a velocidade vertical das parcelas de ar, que é umas das variáveis prognósticas do modelo atmosférico BRAMS. A velocidade vertical da partícula é necessária para o cálculo da sedimentação gravitacional associado à força da gravidade. Este processo remove eficientemente da atmosfera os aerossóis de maior tamanho.
Além da sedimentação gravitacional, há outros dois processos de remoção das cinzas: deposição seca e deposição úmida. A deposição seca refere-se aos processos de remoção dentro da camada limite atmosférica superficial, sem a participação de água líquida, onde processos físicoquímicos induzem à coleta de particulado pela superfície. $\mathrm{O}$ processo de deposição úmida se refere aos processos em que as cinzas são embebidas em gotas de água líquida ou partículas de gelo precipitantes, removendo-as da atmosfera e depositando na superfície. No presente trabalho, este último processo não é contemplado, sendo sua inclusão deixada para trabalhos futuros. A negligência deste termo pode levar a superestimavas da concentração da classe de cinzas mais finas. Porém, a magnitude desta superestimava é de difícil avaliação, uma vez que dependerá da frequência com que a pluma de cinzas entranha em sistemas convectivos presentes em sua trajetória.

\subsection{Desenvolvimento do modelo}

Esta seção descreve os componentes introduzidos no modelo que o possibilitam fazer a simulação numérica do transporte de cinzas vulcânicas.

\subsubsection{Caracterização das cinzas vulcânicas ejetadas na} atmosfera

O diâmetro das partículas ejetadas na atmosfera é um dos fatores que determinam sua velocidade terminal (Eq. (1)). Em geral, quanto maior a partícula, maior sua velocidade terminal, fazendo com que as partículas maiores caiam mais rapidamente do que as partículas menores de similar formato e densidade. Na ausência de dados especificamente coletados no caso do vulcão estudado neste trabalho, a distribuição de tamanho das partículas ejetadas pelo vulcão Puyehue foi baseado no estudo feito sobre a erupção do vulcão Monte Santa Helena (MSH) ocorrido em 1980 (Lipman et al., 1982). Deste estudo foi elaborada a distribuição de tamanho das partículas ejetadas pelo vulcão (vide Tabela 1). A $5^{\text {a }}$ coluna desta tabela se refere ao nome que a partícula recebe no modelo.

Outro fator que altera a velocidade terminal é a densidade da partícula. Segundo o U.S. Geological Survey (2015) a densidade das cinzas vulcânicas varia de 500 a $1300 \mathrm{~kg} / \mathrm{m}^{3}$ quando secas, e de 1.000 a $2.000 \mathrm{~kg} / \mathrm{m}^{3}$ quando umedecidas e compactadas. No case específico, segundo Barbaro (2012), a densidade das cinzas emitidas pelo vulcão Puyehue variaram de 750 a $903 \mathrm{~kg} / \mathrm{m}^{3}$. Por simplificação, foi definido no modelo o valor de densidade para as cinzas vulcânicas igual a $900 \mathrm{~kg} / \mathrm{m}^{3}$.

\subsubsection{Estimativas da altura de injeção e taxa de emissão}

Para simular a concentração de cinzas vulcânicas e sua distribuição espaço-temporal é necessário definir uma função que estabeleça a quantidade de cinzas emitidas pelo vulcão bem como a localização espacial. Estimativa da quantidade de cinzas emitidas por erupções vulcânicas apresentam grandes incertezas e, por isto, diversos autores 
Tabela 1 - Distribuição do tamanho das partículas.

\begin{tabular}{lccccc}
\hline $\begin{array}{l}\text { Diâmetro da partícula } \\
(\mathrm{mm})\end{array}$ & Phi & $\begin{array}{c}\text { Diâmetro médio da } \\
\text { partícula }(\mathrm{mm})\end{array}$ & $\begin{array}{c}\text { Raio médio da } \\
\text { partícula }(\mathrm{mm})\end{array}$ & Nome da partícula & Porcentagem de massa \\
\hline $2-1$ & $-1 \rightarrow 0$ & 1,5 & 0,75 & ash10 & 2 \\
$1-0,5$ & $0 \rightarrow 1$ & 0,75 & 0,375 & ash9 & ash8 \\
$0,5-0,25$ & $1 \rightarrow 2$ & 0,375 & 0,1875 & ash7 & 9 \\
$0,25-0,125$ & $2 \rightarrow 3$ & 0,1875 & 0,09375 & ash6 & 9 \\
$0,125-0,0625$ & $3 \rightarrow 4$ & 0,09375 & 0,04688 & ash5 & 11 \\
$0,0625-0,0312$ & $4 \rightarrow 5$ & 0,04685 & 0,02343 & ash4 & 16 \\
$0,0312-0,0156$ & $5 \rightarrow 6$ & 0,0234 & 0,0117 & ash3 & 16 \\
$0,0156-0,0078$ & $6 \rightarrow 7$ & 0,0117 & 0,00585 & ash2 & ash1 \\
$0,0078-0,0039$ & $7 \rightarrow 8$ & 0,00585 & 0,00293 & 0,00098 & 10 \\
$<0,0039$ & $>8$ & 0,00195 & & & 10 \\
\hline
\end{tabular}

Fonte: baseado no Lipman et al. (1982).

estudaram a existência de uma possível correlação entre a altura de injeção e taxa de emissão. Webster et al. (2012) discutem diversas correlações existentes entre estes dois parâmetros e destacam as seguintes:

$$
\begin{aligned}
& H=0,365 M^{0,225}, \text { (VAFTAD) } \\
& H=0,3035 M^{0,241}, \text { (Mastin) } \\
& H=0,220 M^{0,259}, \text { (Sparks) }
\end{aligned}
$$

onde $H$ é a altura de injeção das cinzas vulcânicas em km e $M$ a taxa de emissão em kg/s. Por outro lado, Mastin et al. (2009) apresentam nas Tabelas 1 e 3 do artigo deles, valores de altura de injeção e taxa de emissão. Com os dados da primeira tabela foi obtido a correlação $H=0,28 \pm$ $0,09 M^{0,245 \pm 0,019}$, ou em uma notação mais concisa

$$
H=0,28(9) M^{0,245(19)} \text { (Claudio1) }
$$

utilizando os dados fornecidos pela terceira tabela do artigo do Mastin foi encontrado a correlação:

$$
H=0,37(13) M^{0,228(24)} \text { (Claudio2) }
$$

e com os dados da tabela 2 de Devinish et al. (2012) foi possível encontrar a correlação:

$$
H=0,61(19) M^{0,204(27)} \text { (Devinish) }
$$

Alterando o valor de $M$ para cada uma das correlações encontradas pode-se observar o comportamento das diferentes correlações, Fig. 2. Para cada correlação há 1300 pontos. Fig. 2 é

A função de reta que melhor representa os pontos da

$$
y=-0,469(2)+0,2337(2) x
$$

Pelo fato do gráfico estar em escala logarítmica, há de se transformar a equação de reta encontra; procedimento análogo foi utilizado em Pavani (2014), descrito pelas equações (4.1) a (4.9). Fazendo a transformação é obtido:

$$
H=0,34(1) M^{0,2337(2)}
$$

A incerteza nesta formula se justifica devido a fatores como a diversidade de fatores que determinam a variabilidade natural dos fenômenos, assim como erros inerentes aos processos de medição dos dados.

\subsubsection{Incerteza em relação à taxa de emissão}

Com o intuito de tornar o modelo mais simples e robusto, foi escolhido um caminho numérico para calcular a incerteza, diferentemente do que foi utilizado em Pavani 2014. Desta forma, para calcular a incerteza em relação à taxa de emissão basta isolar a taxa de emissão na Eq. (8), fazendo isto se obtêm a Eq. (9).

$$
M=\left(\frac{H}{0,34(1)}\right)^{\frac{1}{0,2337(2)}}
$$

O valor máximo de $M$ será de tal forma que ao variar a incerteza dos valores da Eq. (9), o resultado seja o máximo valor, isto resulta em:

$$
M=\left(\frac{H}{0,33}\right)^{\frac{1}{0,2335}}
$$

e o valor mínimo de $M$ resulta em:

$$
M=\left(\frac{H}{0,35}\right)^{\frac{1}{0,2339}}
$$

Aplicando as Eqs. (9)-(11) aos dados observados de altura de injeção, obtemos a Fig. 3.

\subsubsection{Incerteza em relação à altura de injeção}

Para calcular o valor máximo e mínimo da altura de injeção, basta colocar o valor máximo e mínimo de taxa de emissão (Eq. (10) e Eq. (11)) na Eq. (8). Aplicando aos dados observados obtemos a Fig. 4 
Altura de injeção por taxa de emissão para diferentes correlações existentes.

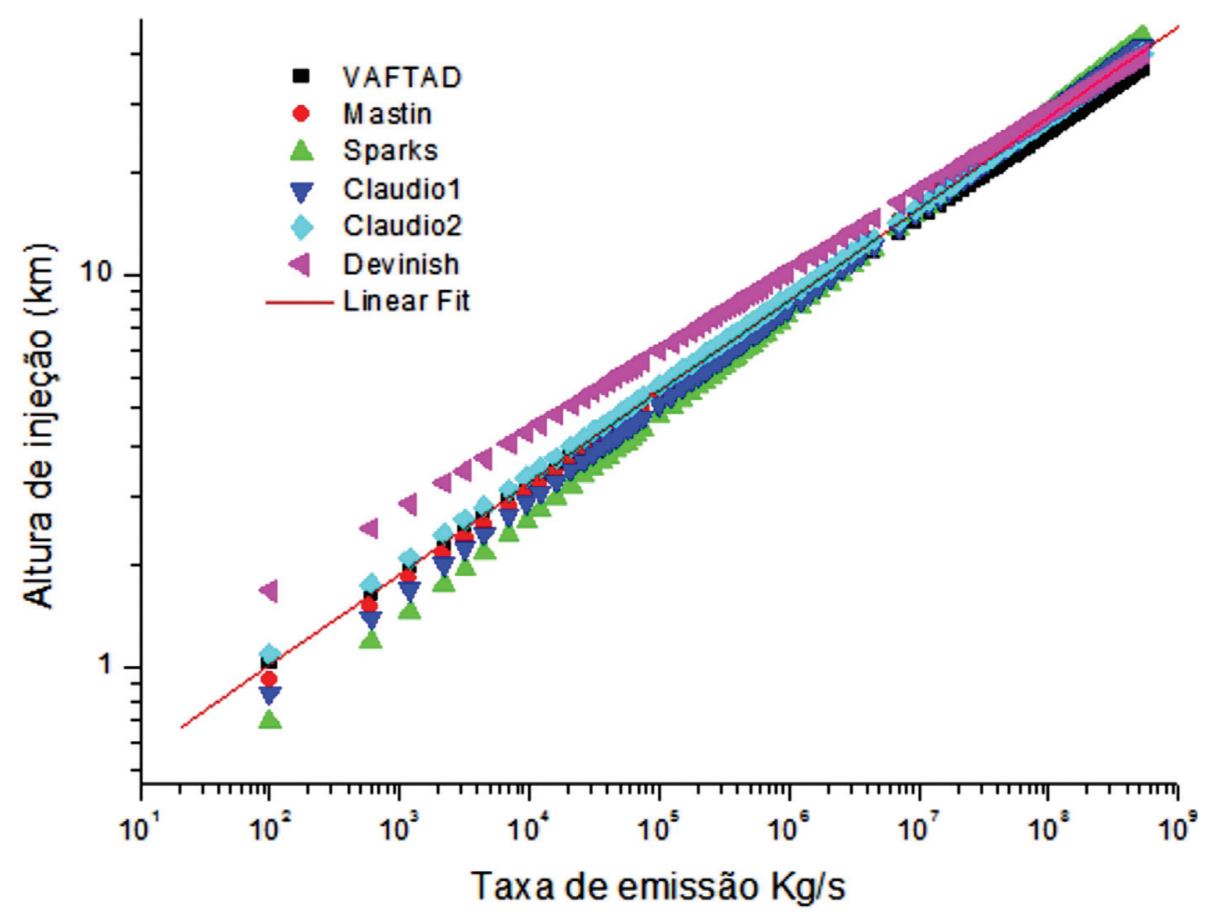

Figura 2 - Altura de injeção por taxa de emissão para diferentes correlações.

As Figs. 3 e 4 mostram que a incerteza nos dados de entrada devido à incerteza na correlação entre taxa de emissão e altura de injeção é pequena (Eq. (8)), tornando desnecessário fazer um ensamble da dispersão das cinzas vulcânicas.

\subsubsection{Distribuição das partículas na coluna ejetada}

No artigo do Stuefer et al. (2013) foi proposta uma distribuição de partículas emitidas pelo vulcão da seguinte forma: $25 \%$ da massa emitida é distribuída linearmente por toda a coluna abaixo da camada de injeção, e $75 \%$ da massa é distribuída na camada de injeção cujo formato quando

\section{Taxa de emissão $(\mathrm{kg} / \mathrm{s})$}

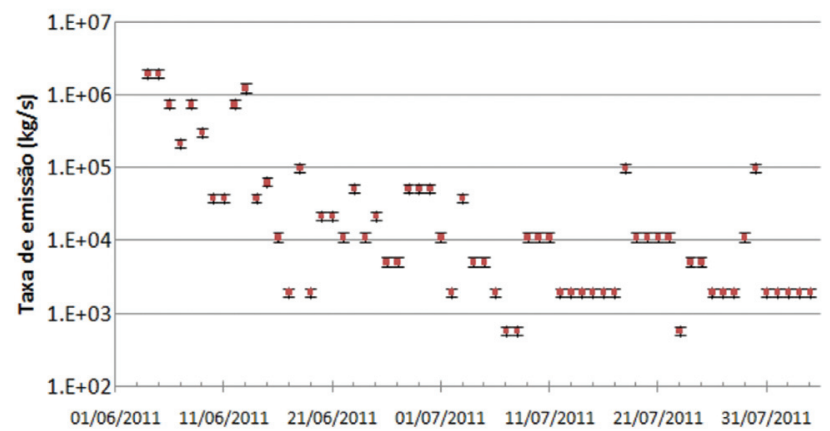

Dia

Figura 3 - Taxa de emissão do vulcão Puyehue com sua respectiva incerteza. projetado num plano é representado por uma parábola, como mostrado na Fig. 5. A ideia por trás desta simples distribuição é a de que esta se assemelha ao formato de um "cogumelo" ou "guarda-chuva" visto comumente em imagens de erupções vulcânicas.

\subsection{Análise de sensibilidade}

Com o intuito de encontrar a melhor configuração, em termos de parametrizações físicas, esquemas de transporte e dos dados de entrada para iniciação e condição de fronteira, do modelo BRAMS para a modelagem do trans-

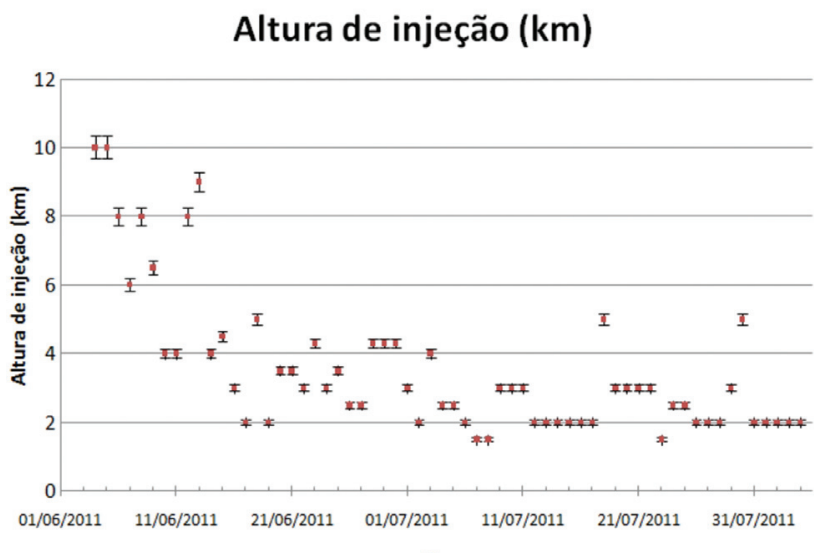

Dia

Figura 4 - Altura de injeção das cinzas vulcânicas com sua respectiva incerteza. 


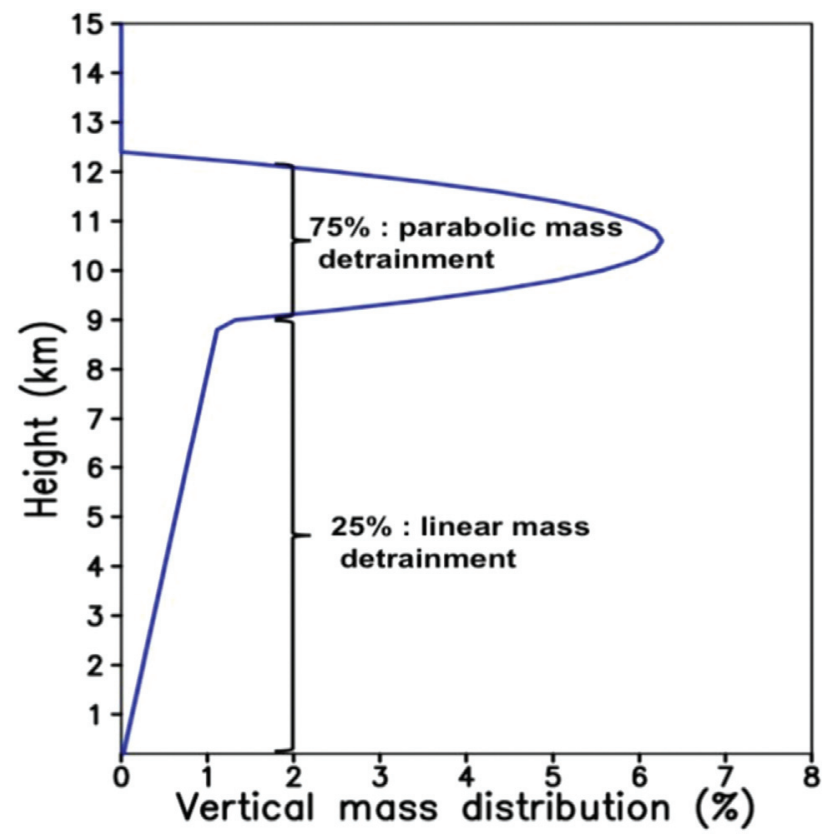

Figura 5 - Distribuição vertical da massa de cinzas vulcânicas para um caso de uma erupção com altura de injeção de 10,5 km.

porte e sedimentação de cinzas vulcânicas, foram feitas estudos de sensibilidade. Com este objetivo, foram modificados alguns parâmetros e configurações, sendo esta análise dividida em três partes:

a) Sensibilidade ao esquema numérico de advecção.

b) Sensibilidade à origem dos dados usados na condição de contorno (cc).

c) Sensibilidade à forma de assimilação dos dados que compõem a cc.

O item "a" refere-se a comparação com o novo esquema de advecção (Freitas et al., 2012), que preserva a monotonicidade do campo de razão de mistura, com o esquema original do modelo BRAMS/RAMS, o qual não é monotônico e apresenta alta difusão numérica. O novo esquema numérico de advecção preserva a monoticidade do campo transportado, introduzindo pouca difusão numérica. Isto faz com que a advecção monotônica seja mais apropriada para simular o transporte de material emitido por fontes de aerossóis extremamente localizadas que produzem, por consequência, distribuição de massa de traçadores com altos gradientes espaciais.

O item "b" refere- se ao uso de análises meteorológicas provenientes de diferentes modelos globais para prover a condição inicial e de contorno do modelo regional. Estas condições de contorno se dividem em:

i. Análises do CPTEC e reanálises do ECMWF

Neste item, as condições iniciais de contorno foram providas por duas fontes: A primeira são Análises recebidas do NCEP e processadas pelo CPTEC, esta análise possui aproximadamente $50 \mathrm{~km}$ de resolução horizontal. E a segunda são reanálises ERA do ECMWF, com 1,5 de resolução espacial na horizontal, aproximadamente $166 \mathrm{~km}$ no equador, as quais são comumente utilizadas em simulações de downscaling.

ii. Caso combinando análise + previsão: somente dados do CPTEC.

Este caso aplica a situação possível em previsões em tempo real, no qual a análise do modelo global do CPTEC é usada como condição inicial para o modelo regional, enquanto que as previsões deste modelo são usadas para prover condição de contorno, ao contrário do caso anterior no qual a condição de fronteira era fornecida pela análise global. Este experimento permite verificar se é de utilidade prática implementar um produto operacional em tempo real, sob demanda, para o monitoramento e previsão do transporte de cinzas vulcânicas. A razão para tal experimento decorre do fato de que este produto seria de grande valia para a aviação civil e militar e sistemas de alerta em geral. Foram utilizadas as análises do CPTEC e não as do ECMWF, pois foi a melhor condição de contorno obtida conforme discutido no sub-item anterior (i. Análises do CPTEC e reanálises do ECMWF).

O item "c" se refere a mudar a forma como os dados são introduzidos na região de contorno. Existem duas formas de fazer este procedimento no BRAMS: o processo de assimilação via relaxação Newtoniana (nudging) somente nos pontos próximos à fronteira, conhecido como relaxação lateral, e via relaxação no centro da grade. Na relaxação lateral o modelo regional sofre a influência do modelo global somente sobre as bordas laterais e numa camada vertical próxima ao topo da grade. No tipo relaxação lateral mais central, os dados de análise ou previsão do modelo global influenciam tanto nas bordas como no centro do modelo regional, sendo que no centro a influência é tipicamente mais fraca, ou seja, o intervalo de relaxação é mais longo. No caso do BRAMS o processo de relaxação é realizado na equação de tendência das variáveis prognósticas com a introdução do seguinte termo:

$$
N=\left(\frac{v_{0}-v}{\Delta T}\right)
$$

em que $\left(v_{0}\right)$ é o valor expresso no dado do modelo global e analisado na grade do modelo regional; $(v)$ o valor prognosticado no passo de tempo anterior pelo modelo regional; $(\Delta T)$ representa escala de tempo em que esta influência será aplicada. Quanto maior o valor de $(\Delta T)$, menor a influência da assimilação no modelo. Esta influência altera a o prognóstico final segundo a Eq. (13):

$$
\frac{\partial \vec{v}}{\partial t}=F+D+N
$$

na qual $(F)$ representa a mudança temporal da variável devido aos processos físicos do modelo, $(D)$ a mudança temporal da variável devido aos termos de dinâmica do modelo e $(N)$ a mudança temporal da variável devido a contribuição da relaxação. No presente estudo, o valor de 
$(\Delta T)$ para região lateral é 900 segundos, o que significa forte influência, e foram testados para a região interna os valores de 43.200 segundos, influência fraca, e 3.600 segundos, influência mediana. Foi selecionado que a influência lateral atua sobre uma borda de 25 pontos de grade.

\section{Resultados e Discussão}

Após incluir funcionalidades no modelo BRAMS para capacitá-lo a simular a dispersão das cinzas vulcânicas, foram feitos experimentos de análise de sensibilidade com o intuito de obter a melhor configuração, conforme descrito anteriormente.

\subsection{Sensibilidade ao esquema numérico de advecção}

Com o intuito de verificar se uma advecção monotônica agrega maior acurácia nas simulações do transporte de cinzas vulcânicas, visto que são computacionalmente muito mais caras, foram produzidos dois experimentos: um com advecção original, não monotônica (ADVMNT OFF ou apenas OFF) e outro com advecção monotônica (ADVMNT ON ou apenas ON). Nestes experimentos foram buscadas situações com oscilações espúrias no campo de razão de mistura dos aerossóis vulcânicos causadas por instabilidade numérica ou pela presença de modos computacionais no esquema numérico de diferenças finitas. Regiões do domínio do modelo com intenso gradiente da concentração de aerossóis, são locais onde potencialmente podem surgir oscilações espúrias, semelhantes as oscilações de Gibbs em métodos espectrais (Freitas et al., 2012). Além disto, foram realizadas comparações qualitativas da posição espacial da pluma vulcânica simulada com a posição espacial da pluma detectada pelos satélites CALIPSO e Meteosat-8.

As simulações com o modelo BRAMS foram realizadas com espaçamento de grade de $30 \mathrm{~km}$ na horizontal no período de 04/06/11 até 19/06/11. Para tornar mais evidente à ocorrência de oscilações numéricas, unicamente neste experimento, a difusão numérica mínima na horizontal foi alterada para $1 \%$ do valor normalmente aplicado (veja maiores detalhes no apêndice B de Freitas et al., 2012). Observando a Fig. 6, nota-se claramente que foram geradas oscilações espúrias para advecção OFF e o mesmo não ocorreu no experimento ON. Ou seja, do ponto de vista numérico a nova advecção é mais apropriada para o transporte de traçadores com distribuição da massa localizada. Foram encontradas oscilações espúrias unicamente no perfil vertical, pois este possui menor resolução espacial comparado ao perfil horizontal.

Para verificar do ponto de vista observacional qual esquema numérico de advecção é preferível, foram utilizados dados do satélite CALIPSO, pois este detecta com maior precisão a posição dos aerossóis na atmosfera.

No dia 05 de junho de 2011 entre às 05:59 e 06:00Z o satélite CALIPSO observou uma pluma de cinzas vulcâ- nicas. A linha reta em vermelho da Fig. 7 indica a trajetória do satélite, escala de cores representa a quantidade de cinzas integrada na coluna atmosférica simulado pelo modelo em unidades de $\mu \mathrm{g} / \mathrm{m}^{2}$ e o ponto A representa o início da trajetória. A posição das cinzas sobre esta trajetória, Fig. 8, é comparado com a posição da pluma observada pelo satélite, Fig. 9.

A Fig. 8 mostra que as cinzas se concentram aproximadamente nas latitudes de $-40,4^{\circ}$ a $-41,4^{\circ}$ e longitude de $-71,0^{\circ}$ a $-71,3^{\circ}$ a $12 \mathrm{~km}$ de altura. A altitude do terreno nesta região para $30 \mathrm{~km}$ de resolução é 939,45 m, ou seja, aproximadamente $1 \mathrm{~km}$, logo, as cinzas vulcânicas se encontram em torno de $13 \mathrm{~km}$ de altitude. Pode-se observar que houve uma dispersão maior da pluma vulcânica na simulação com advecção não monotônica (Fig. 8 à direita).

Também pode-se observar na Fig. 9 que os aerossóis estratosféricos, representados em cor amarela, que neste caso são constituídos primariamente de cinzas vulcânicas, encontram-se em grandes concentrações, pois o sinal de retroespalhamento foi totalmente atenuado. A localização das cinzas vulcânicas está entre 12 e $13 \mathrm{~km}$ de altitude, detectada sobre a latitude de $-40,9^{\circ}$ à $-41,4^{\circ}$ e longitude $-71,0^{\circ}$ à $-71,2^{\circ}$ sobre a trajetória indicada na Fig. 7. É possível observar que não ocorre propagação de cinzas para latitudes inferiores a $-41,4^{\circ}$. Comparando com a Fig. 8 pode-se inferir que a advecção monotônica apresenta resultados mais realísticos que o esquema numérico original de advecção, pois na advecção original ocorre uma propagação acentuada de cinzas para latitudes menores que $-41,4^{\circ}$, o que não ocorre nas observações por satélite. Em geral, a advecção monotônica foi melhor nos casos analisados e, alguns destes, são descritos em Pavani (2014).

\subsection{Sensibilidade à fonte de condição de contorno (cc).}

- Caso I: Análise CPTEC e reanálise ERA do ECMWF

Este experimento tem por finalidade avaliar qual a melhor condição de contorno atmosférica para simular o transporte de cinzas: análises do NCEP/CPTEC ou reanálises do ERA/ECMWF.

Foram feitas duas simulações cada uma com $30 \mathrm{~km}$ de resolução horizontal, durante 15 dias e iniciadas com as condições do dia 04 de junho de 2011. Não foi aplicada relaxação no centro da grade, diferenciando entre as duas simulações apenas a fonte de dados usados para a condição de contorno lateral. Com o intuito de averiguar qual a melhor condição de contorno, os resultados gerados pelo modelo foram comparados com dados observados, principalmente dados do CALIPSO devido sua maior precisão na localização espacial dos aerossóis.

Comparando o resultado do modelo para o caso já descrito do dia 05 de junho de 2011, pode-se observar que a aplicação da condição de contorno fornecida pela análise do CPTEC levou a melhores resultados que com a condição de contorno do ECMWF (Fig. 10). Neste último caso, 
Concentração de cinzas do tipo 6 às 09Z no dia 07 de junho de 2011

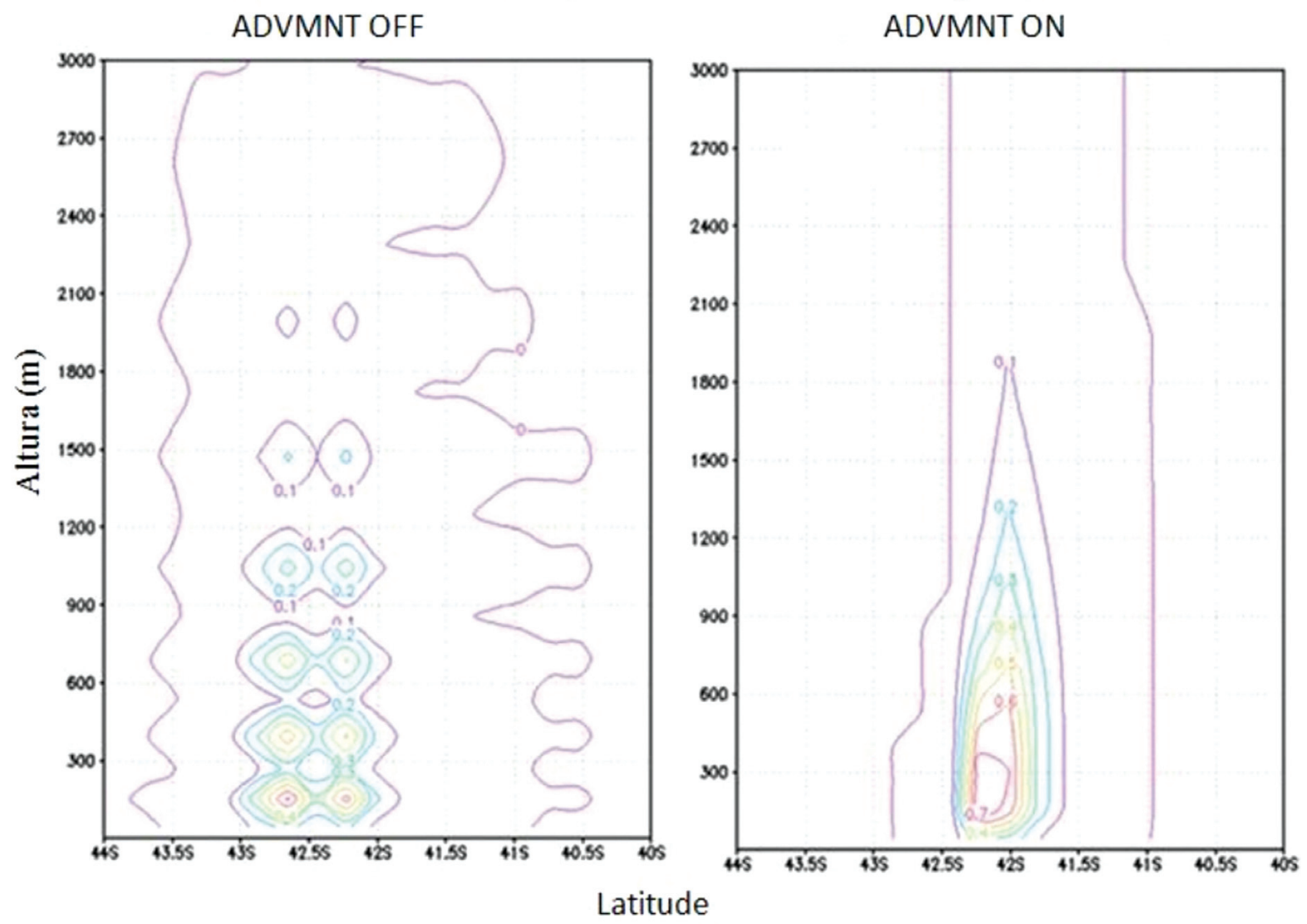

Figura 6 - Concentração vertical de cinzas do tipo $6\left(\mathrm{em} \mu \mathrm{g} / \mathrm{m}^{3}\right)$ na longitude de $-66.7^{\circ}$ no dia $07 / 06 / 2011$. À esquerda é mostrado resultado com esquema numérico de advecção original (ADVMNT OFF), à direita o resultado com o esquema com advecção monotônica (ADVMNT ON).

Concentração de cinzas vulcânicas na coluna atmosférica.

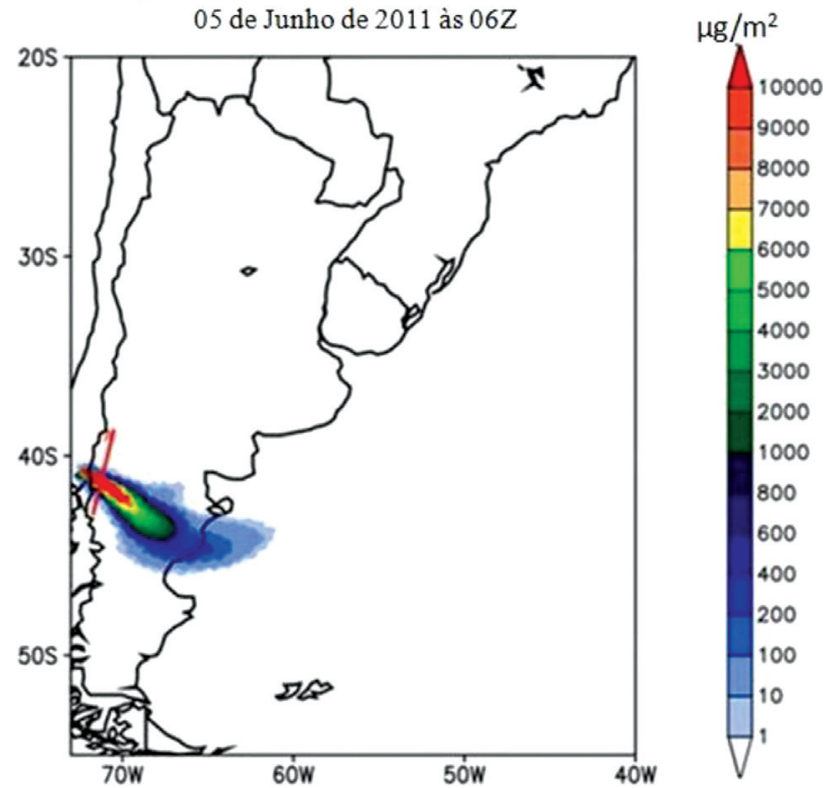

Figura 7 - Concentração de cinzas vulcânicas integrado na coluna atmosférica utilizando advecção monotônica. houve uma menor concentração de cinzas ao sul de $-41,4^{\circ}$ que, não foi detectada nas observações por satélite (Fig. 9). Em todos os casos analisados, a evolução da distribuição espacial da concentração de aerossóis vulcânicos ficou mais próxima dos campos observados pelos sensores do CALIPSO quando foi utilizado a condição de contorno proveniente do CPTEC (vide análise de outros casos em Pavani 2014).

A análise CPTEC produziu um melhor desempenho ao modelo regional, pois a resolução espacial é maior. Análise CPTEC possui $50 \mathrm{~km}$ e o ERA-ECMWF aproximadamente166 km. A resolução horizontal mais alta na região de relaxação newtoniana lateral permite que estruturas sinóticas de menor escala sejam introduzidas no interior do domínio, afetando a evolução temporal da concentração dos aerossóis vulcânicos.

-Caso II: Dados de análise na condição inicial e de previsão na condição de fronteira (CPTEC)

Este experimento tem por finalidade observar o quanto a previsão do modelo regional se distancia do observado, ao substituir a condição de fronteira dada pela análise por uma condição oriunda de previsões do modelo global do CPTEC. Este experimento tem o intuito de mensurar se o 


\section{Concentração de cinzas vulcânicas fornecido pelo modelo sobre a trajetória do satélite.}

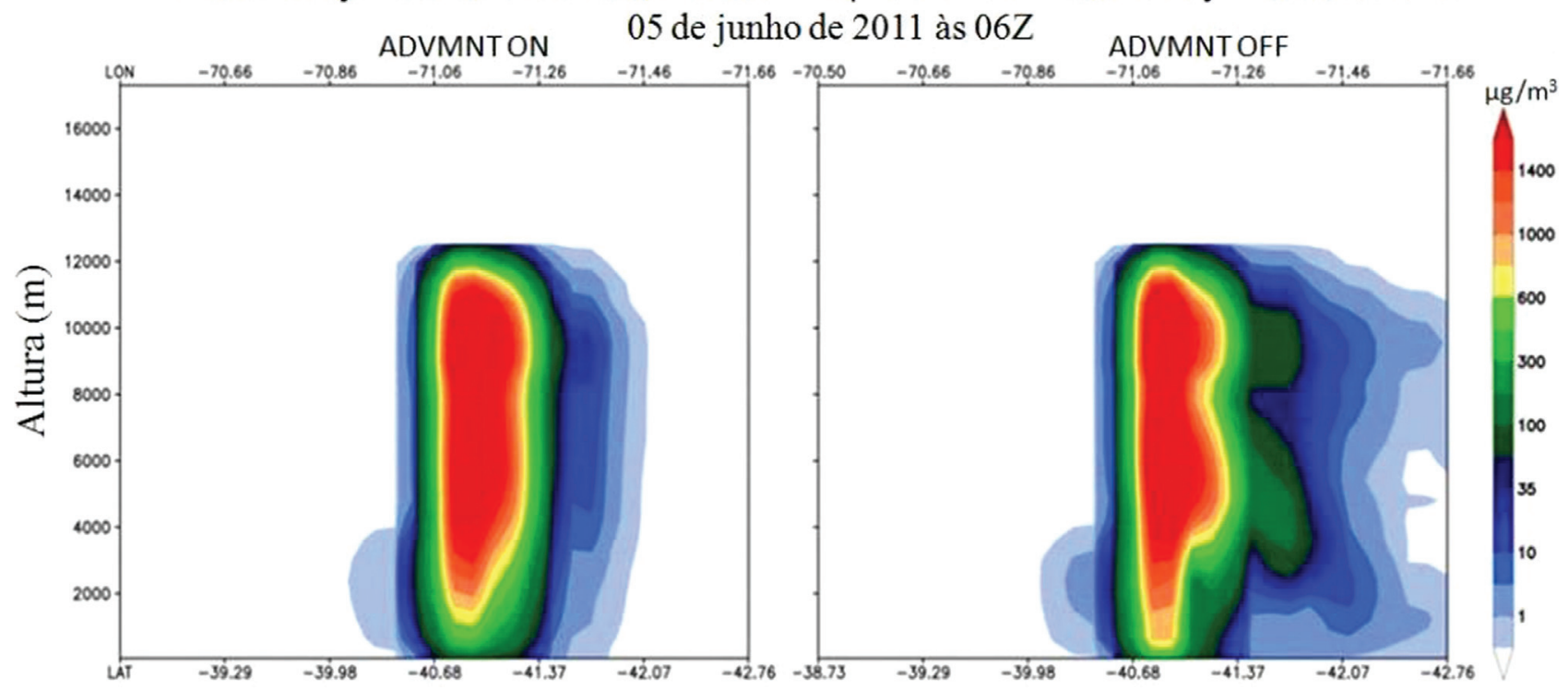

Figura 8 - Perfil vertical da concentração de cinzas vulcânicas $\left(\mu \mathrm{g} / \mathrm{m}^{3}\right)$ sobre a trajetória do satélite. Esquerda simulação realizada com advecção monotônica. Direita advecção original do BRAMS.

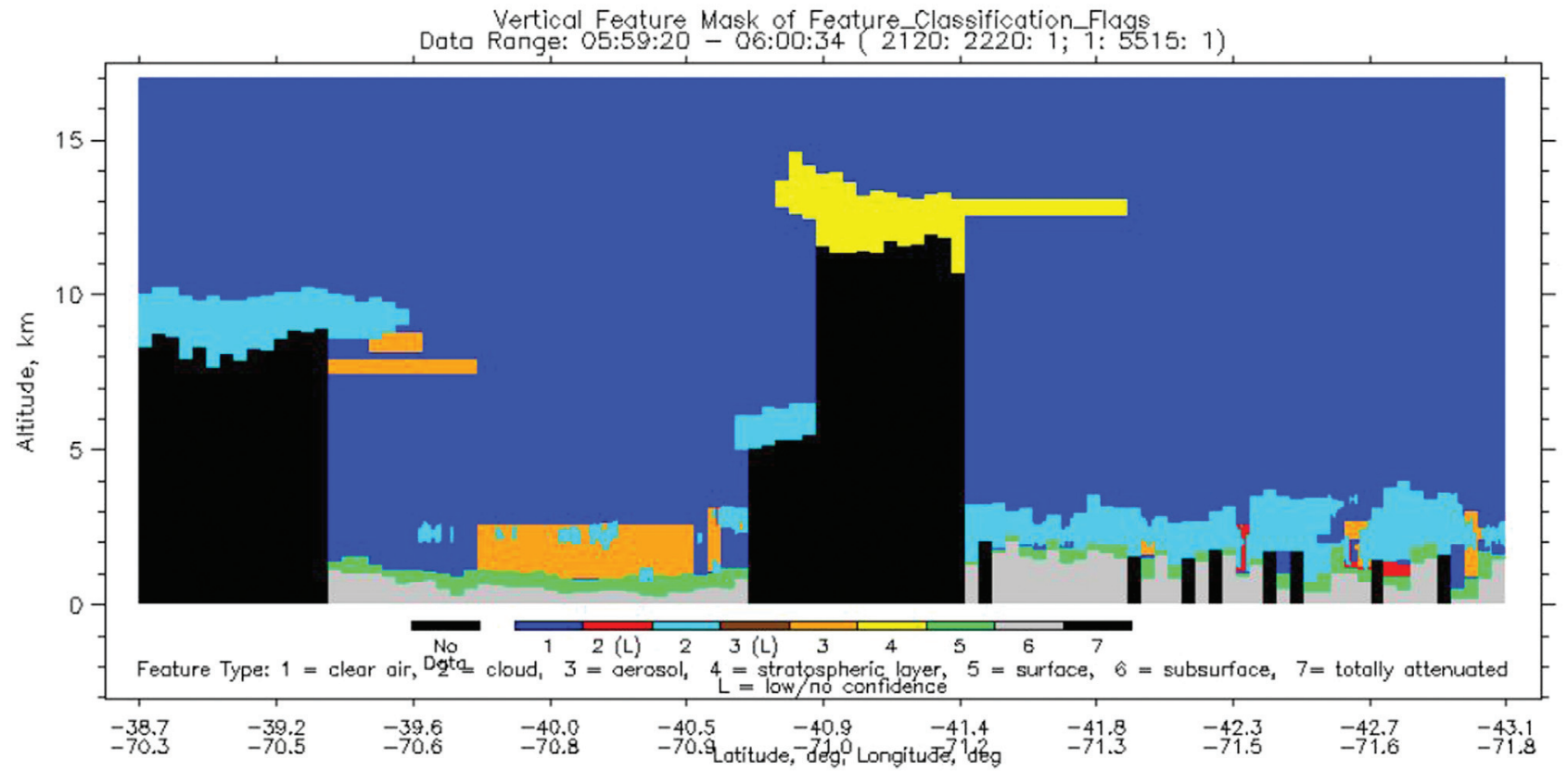

Figura 9 - Perfil vertical dos aerossóis observados pelo satélite CALIPSO. Em amarelo está "stratospheric layer", que neste caso representa cinzas vulcânicas. A mancha preta significa que não foi possível observar, pois o sinal de retroespalhamento foi totalmente atenuado.

modelo é capaz de prever com acurácia a posição das cinzas vulcânicas. Foram simulados 10 casos de previsões de 7 dias, iniciando em dias sucessivos a começar pelo dia 04 de junho de 2011. Manteve-se a resolução horizontal de $30 \mathrm{~km}$ no modelo regional assim como os demais parâmetros que definem a relaxação newtoniana. Neste caso não foi aplicada a relaxação no interior do domínio.
$\mathrm{Na}$ análise de regiões próximas da fonte emissora com distâncias inferiores a $3.000 \mathrm{~km}$ não foram identificadas diferenças significativas entre os casos com análise e previsão na condição de fronteira (Pavani 2014). Entretanto é preciso avaliar se o modelo é capaz de prever adequadamente transporte por distâncias mais longas, como, por exemplo, em que impliquem na introdução de cinzas vulcânicas na atmosfera sobre o Brasil. Utilizando a 


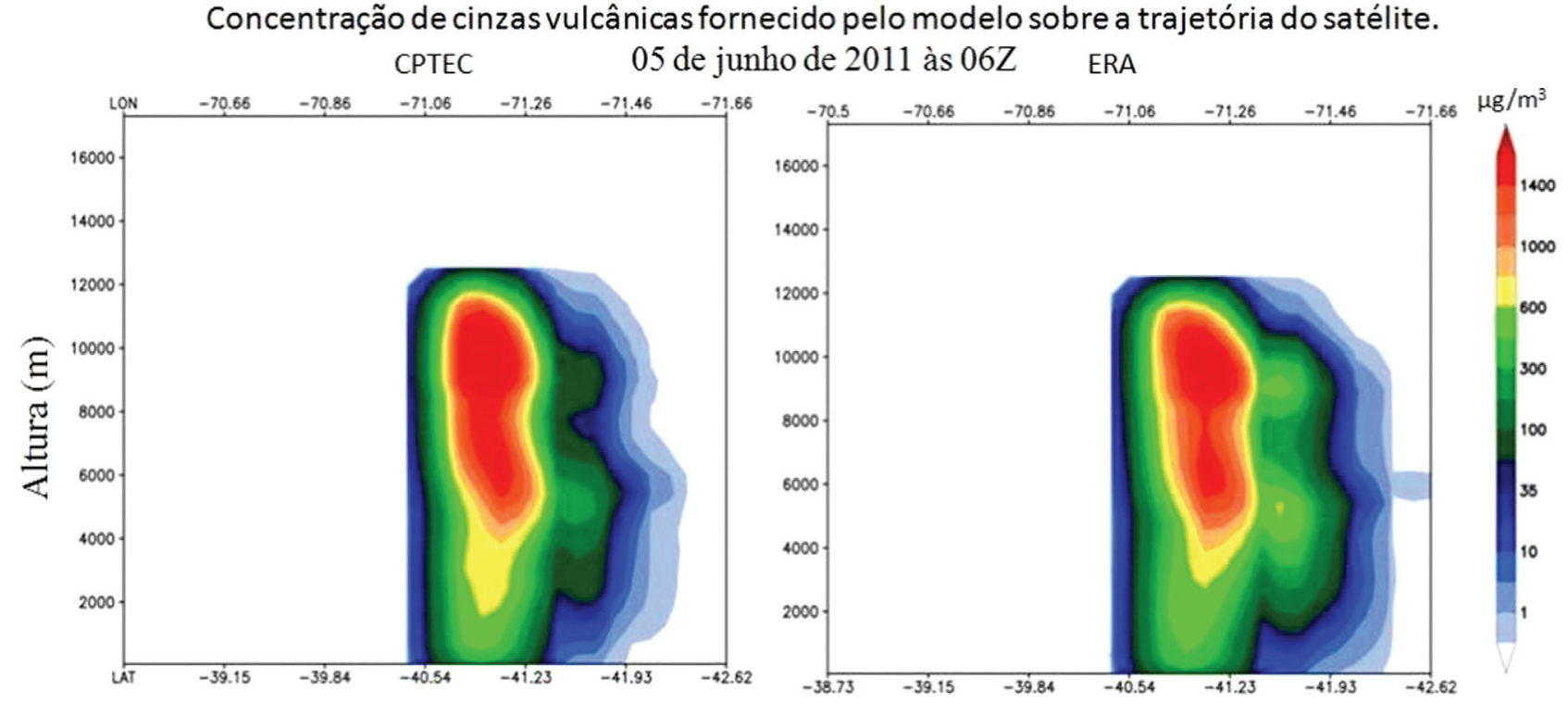

Figura 10 - Concentração de cinzas vulcânicas $\left(\mu \mathrm{g} / \mathrm{m}^{3}\right)$ sobre o trajeto do satélite, representado na Fig. 7. Esquerda simulação utilizando borda análise CPTEC. Direita utilizando a condição de contorno dada pela reanálise do ECMWF (ERA).

imagem fornecida pelo DSA (Fig. 11) pode-se observar a presença de cinzas vulcânicas sobre o litoral sul do país, principalmente sobre a região costeira do estado de Santa Catarina. Vale ressaltar que as cinzas que se encontram abaixo das nuvens não são detectadas por este método. Pelo fato do satélite CALIPSO ter ficado fora de operação no dia 4/06/11 e entre os dias 06/06 ao dia 14/06, não há dados deste satélite para este evento.

Pode-se observar na Fig. 12 que, utilizando previsão do modelo global do CPTEC na condição de fronteira, as cinzas vulcânicas não chegam até o litoral norte de Santa Catarina (neste caso foram 4 dias de previsão), ao contrário do observado por sensoriamento remoto, Fig. 11, que mostra que a pluma vulcânica chegou até a região. Desta forma, a introdução das previsões do modelo global degradam a representação dos sistemas sinóticos pelo modelo regional e, por consequência, a fidelidade no transporte a longas distâncias e longos prazos. Neste caso, uma diferença da ordem de 3 graus na latitude é produzida entre as duas simulações.

Contudo, pode-se afirmar que é possível implementar um sistema emergencial capaz de monitorar e prever a posição das cinzas vulcânicas, desde que se tenha a altura de injeção.

\subsection{Sensibilidade à relaxação newtoniana no interior $\mathrm{e}$ nas bordas do domínio computacional do modelo}

Este experimento tem por finalidade verificar se a relaxação newtoniana no centro (relaxação no centro) melhora a resposta do modelo do ponto de vista do transporte de cinzas vulcânicas. Foram feitas três simulações, com $30 \mathrm{~km}$ de resolução horizontal e 15 dias de simulação a começar pelo dia 04/06/11 às 00Z, diferenciando entre elas apenas a intensidade da relaxação newtoniana na parte interna do domínio, com escalas temporais de relaxação de 43.200 s, 3.600 s ou sem relaxação. Primeiramente será analisado se há melhora ao colocar relaxação no centro e posteriormente será analisado o impacto da intensidade da relaxação central.

A discussão é focada no dia 05 de junho as $18 \mathrm{Z}$. Portanto na previsão de 42 horas após o início da simulação, que coincide com o horário da passagem do satélite CALIPSO sobre a pluma vulcânica (exatamente entre às 17:57 e 17:59Z). A Fig. 13 mostra a trajetória do satélite e a concentração de cinzas vulcânicas (valor integrado na coluna atmosférica) prevista pelo modelo com relaxação central com escala temporal de 43.200 s (aqui denominada de "fraca"). A Fig. 14 provê uma comparação entre os resultados obtidos sem relaxação e com relaxação usando escala de tempo fraca. Observa-se que a localização e extensão horizontal das plumas de cinzas apresentam significativas diferenças. Comparação destes resultados com o observado, Fig. 15, permite notar uma melhora significativa da posição da pluma ao incluir relaxação no centro do domínio computacional.

Uma avaliação posterior de grande utilidade seria aplicar uma intensidade da relaxação newtoniana central de maior valor e verificar o desempenho da resposta do modelo. Neste caso, foi realizado um experimento com escala de tempo de $3.600 \mathrm{~s}$ (ou seja relaxação mais intensa) e comparado com a simulação utilizando relaxação mais fraca no centro, 43.200 s. Próximo ao vulcão não houve diferença significativa entre os dois casos (vide Pavani (2014)) para mais detalhes). Assim, foram analisadas as diferenças entre as simulações em regiões mais distantes do vulcão. Um caso interessante é mostrado na Fig. 16, o qual 


\section{Traços de cinzas do vulcão Puyehue. 08 de junho de 2011 às 00:00 UTC}

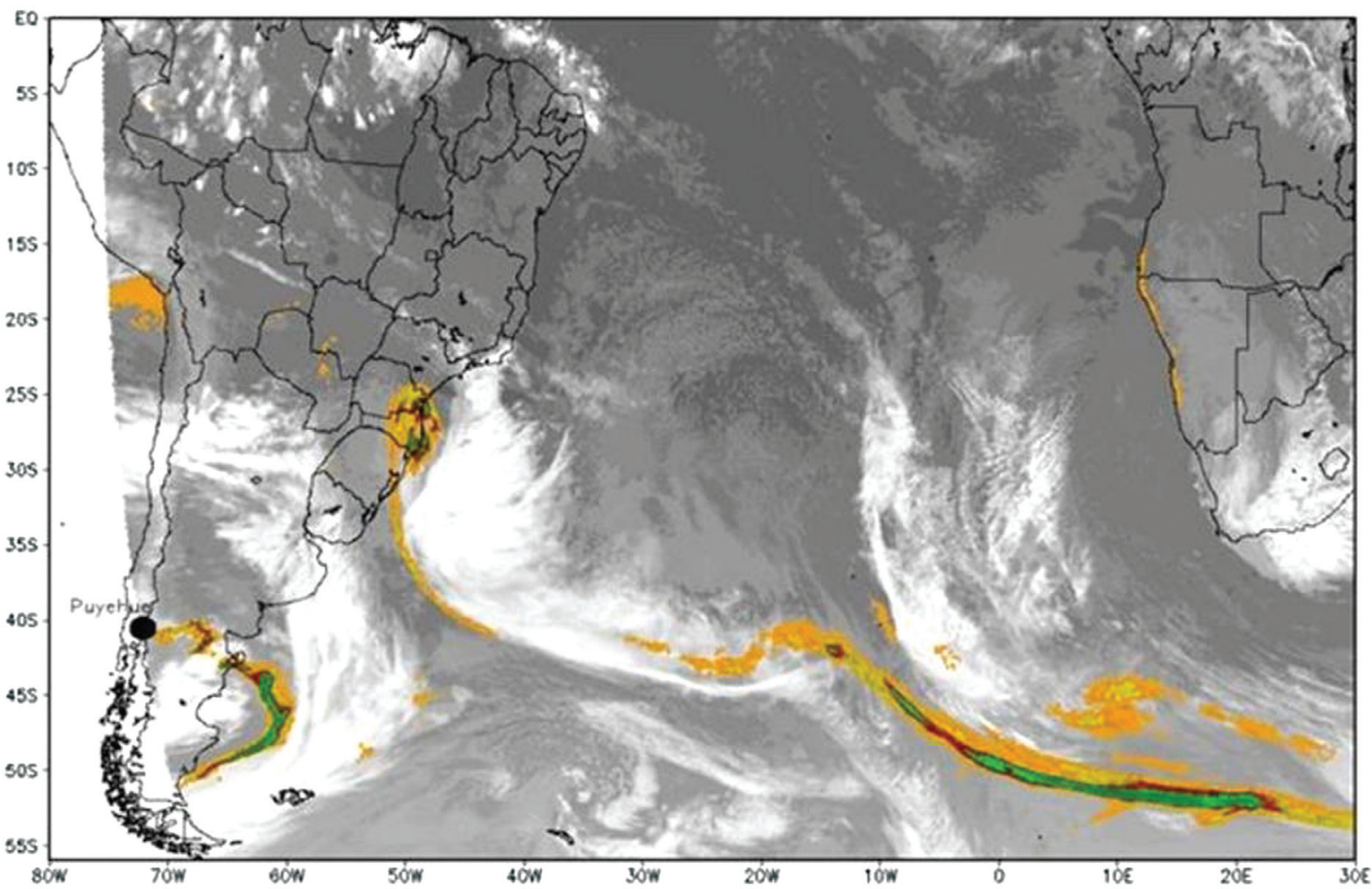

Figura 11 - Composição de IR10 em cinza e IR10-IR12 em colorido. Dia 08 junho de 2011 às 00Z. Fonte DSA/CPTEC.

\section{Concentração de cinzas vulcânicas integrado na coluna atmosférica.}

Análise

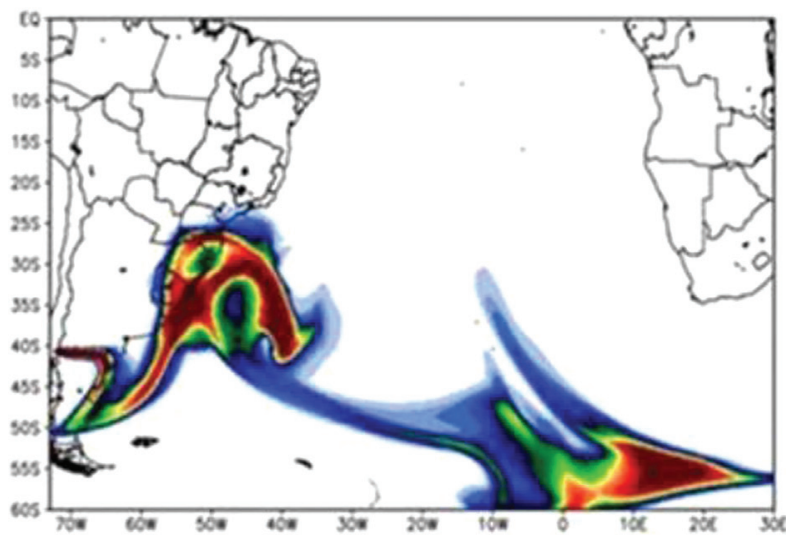

Previsão

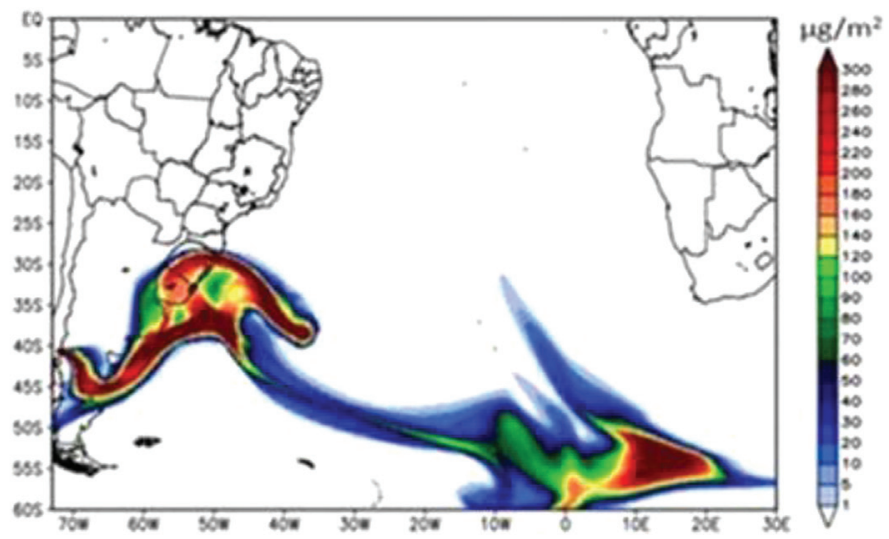

Figura 12 - Quantidade de cinzas integrada na coluna atmosférica $\left(\mu \mathrm{g} / \mathrm{m}^{2}\right)$. Análise e Previsão (quarto dia de previsão).

apresenta uma situação de transporte a longa distância formando um filamento de cinzas acima do topo das nuvens ao sul da África do Sul (região entre $50^{\circ}$ e $52^{\circ}$ sul e entorno de $20^{\circ}$ leste). A imagem se refere ao dia 08 junho de 2011 às 06Z. Nesta figura, o traço vermelho indica o setor onde foi analisado o perfil vertical da concentração de cinzas simulado utilizando relaxação newtoniana forte $(3.600 \mathrm{~s})$ e fraca (43.200 s). Os perfis verticais estão respectivamente repre- sentados na Fig. 17. Observa-se que a simulação denominada forte impõe a pluma com topo localizado significativamente mais alto com um núcleo de partículas mais finas de aproximadamente $200 \mu \mathrm{g} / \mathrm{m}^{3}$. Também pode ser notado que esta pluma se estende para latitudes mais ao norte, porém gradativamente em altitudes mais baixas, do que a correspondente da simulação com relaxação denominada fraca. Esta observação é quantitativamente mostrada 
na Fig. 18 com a diferença da concentração de cinzas vulcânicas (relaxação forte menos relaxação fraca) sobre o perfil vertical analisado.

A Fig. 18 mostra que as cinzas foram deslocadas um pouco mais ao norte, aproximando-se mais do produto derivado das imagens de satélite, conforme indicado na

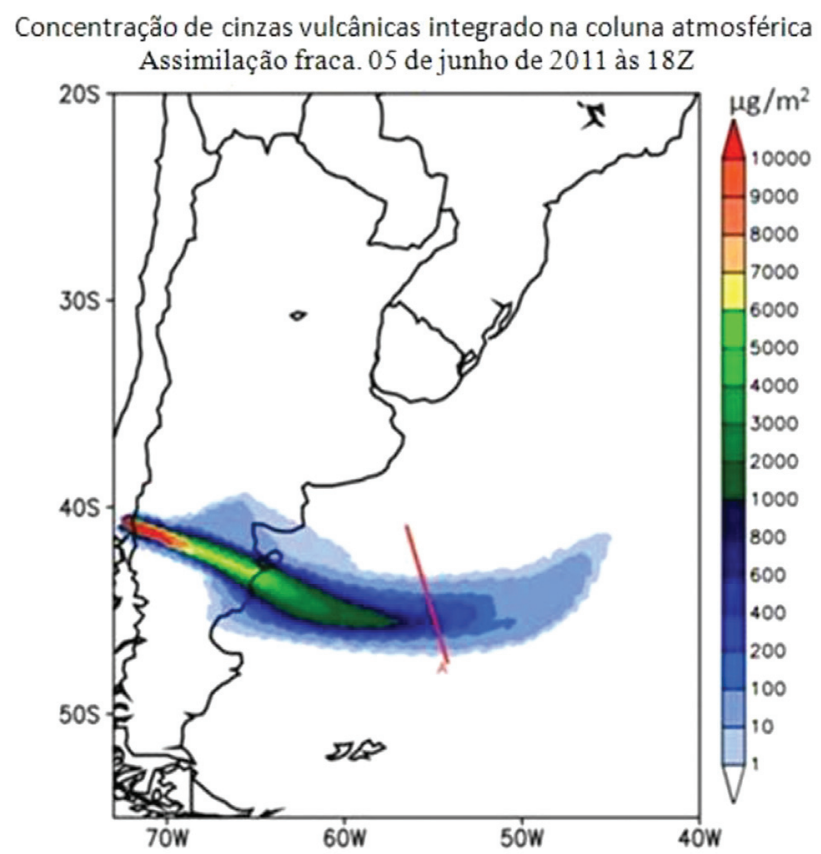

Figura 13 - Concentração de cinzas vulcânicas integrado na coluna atmosférica $\left(\mu \mathrm{g} / \mathrm{m}^{2}\right)$. A linha tracejada representa a trajetória do satélite CALIPSO, sendo "A" o início da trajetória.
Fig. 16. Estes resultados indicam que aplicação de uma relaxação newtoniana mais forte no interior do domínio pode ter impactos substanciais e positivos na acurácia da previsão da localização da pluma de cinzas. No presente caso apresentado, uma explicação plausível é a de que o campo do vento no interior do domínio do modelo foi mantido mais próximo ao campo analisado pelo modelo global do CPTEC.

\section{Conclusões}

Este artigo descreve a inclusão de funcionalidades básicas no modelo BRAMS visando capacitá-lo a simular e prever o transporte, dispersão, sedimentação e deposição seca de cinzas vulcânicas. A nova funcionalidade do modelo é útil em situações reais para monitorar a localização e concentração de cinzas vulcânicas dando apoio às atividades aéreas e auxiliando na estimativa de impactos ambientais. Além disto, esta funcionalidade do modelo pode ser aplicada em estudos científicos de como os principais sistemas sinóticos da América do Sul atuam na redistribuição espacial das emissões de vulcões sul-americanos. Estudos de sensibilidade de configurações de dinâmica e relaxação newtoniana, aplicada nas condições de contorno e na parte central do domínio, foram realizados e suas principais conclusões são resumidas a seguir.

Sobre o experimento referentes a sensibilidade aos esquemas numéricos de advecção, conclui-se que o esquema de advecção com preservação de monotonicidade induz a um substancial ganho de acurácia, tanto no ponto de vista numérico, pois não apresenta oscilações espúrias, como no

\section{Concentração de cinzas vulcânicas fornecido pelo modelo sobre a trajetória do satélite.} 05 de junho de 2011 às $18 Z$
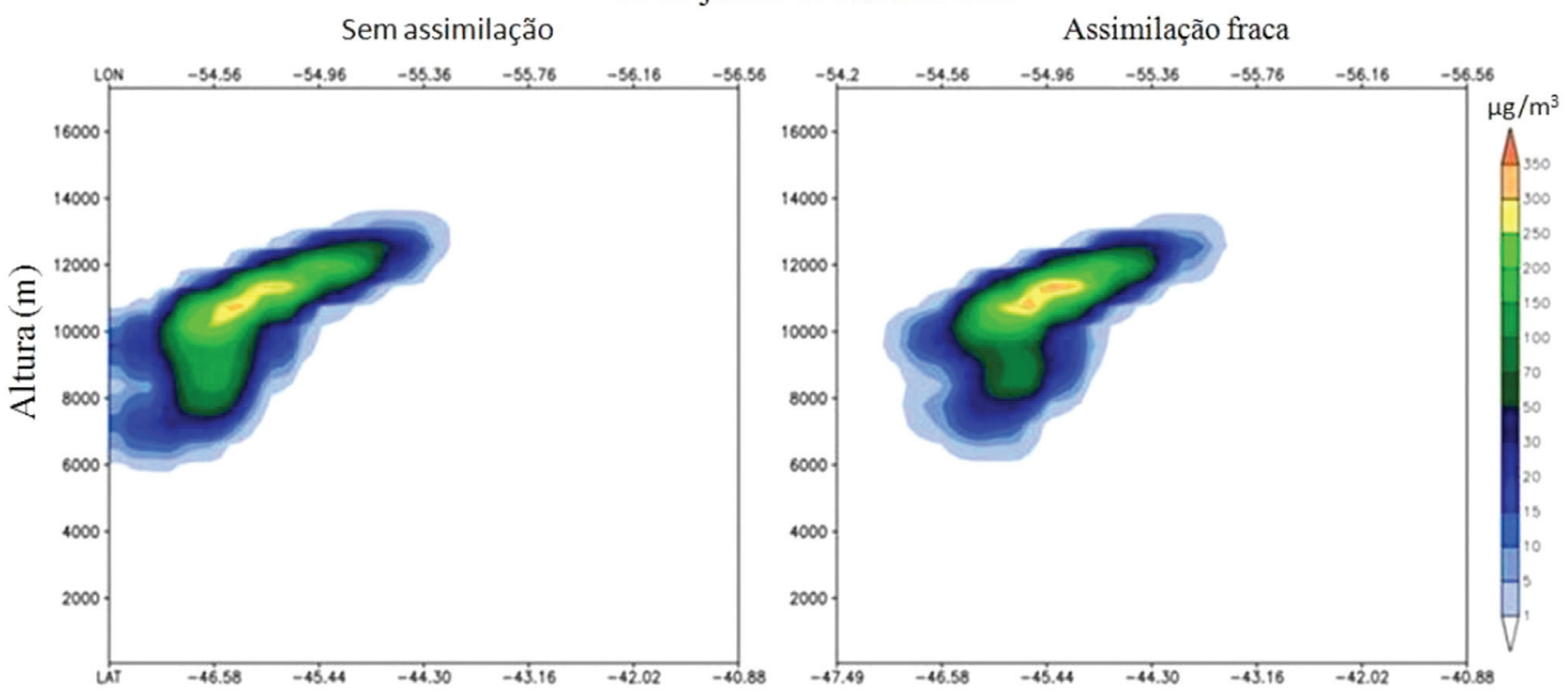

Figura 14 - Perfil vertical da concentração de cinzas vulcânicas $\left(\mu \mathrm{g} / \mathrm{m}^{3}\right)$ sobre a trajetória do satélite representada na Fig. 13. 


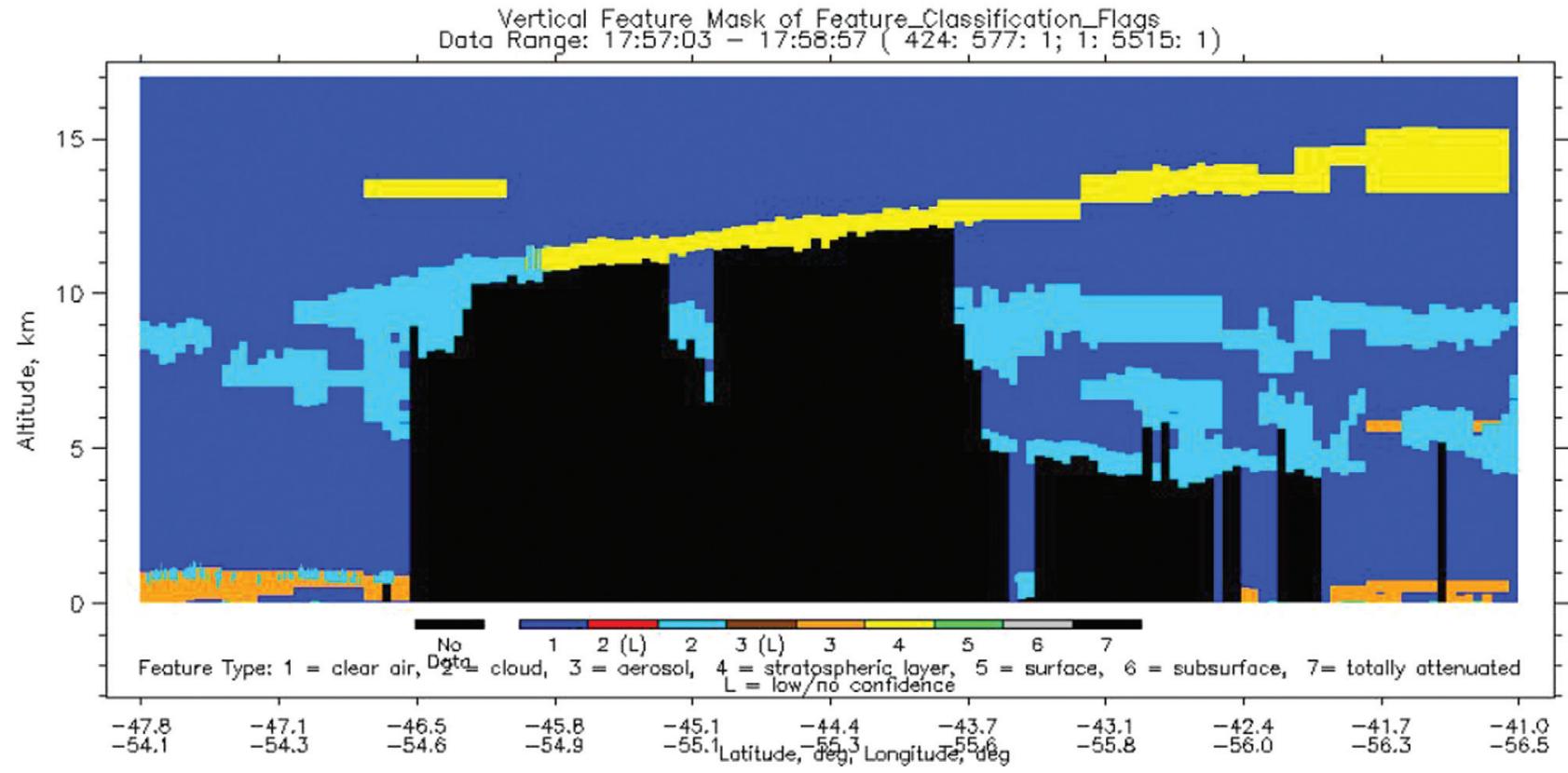

Figura 15 - "Vertical Feature Mask". A mancha amarela representa "stratospheric layer", esta classificação significa tanto nuvens acima da tropopausa como aerossóis. A mancha preta significa que o sinal foi totalmente atenuado devido à absorção ocorrida pela grande concentração de aerossóis.

Traços de cinzas do vulcão Puyehue. 08 de junho de 2011 às 06:00 UTC

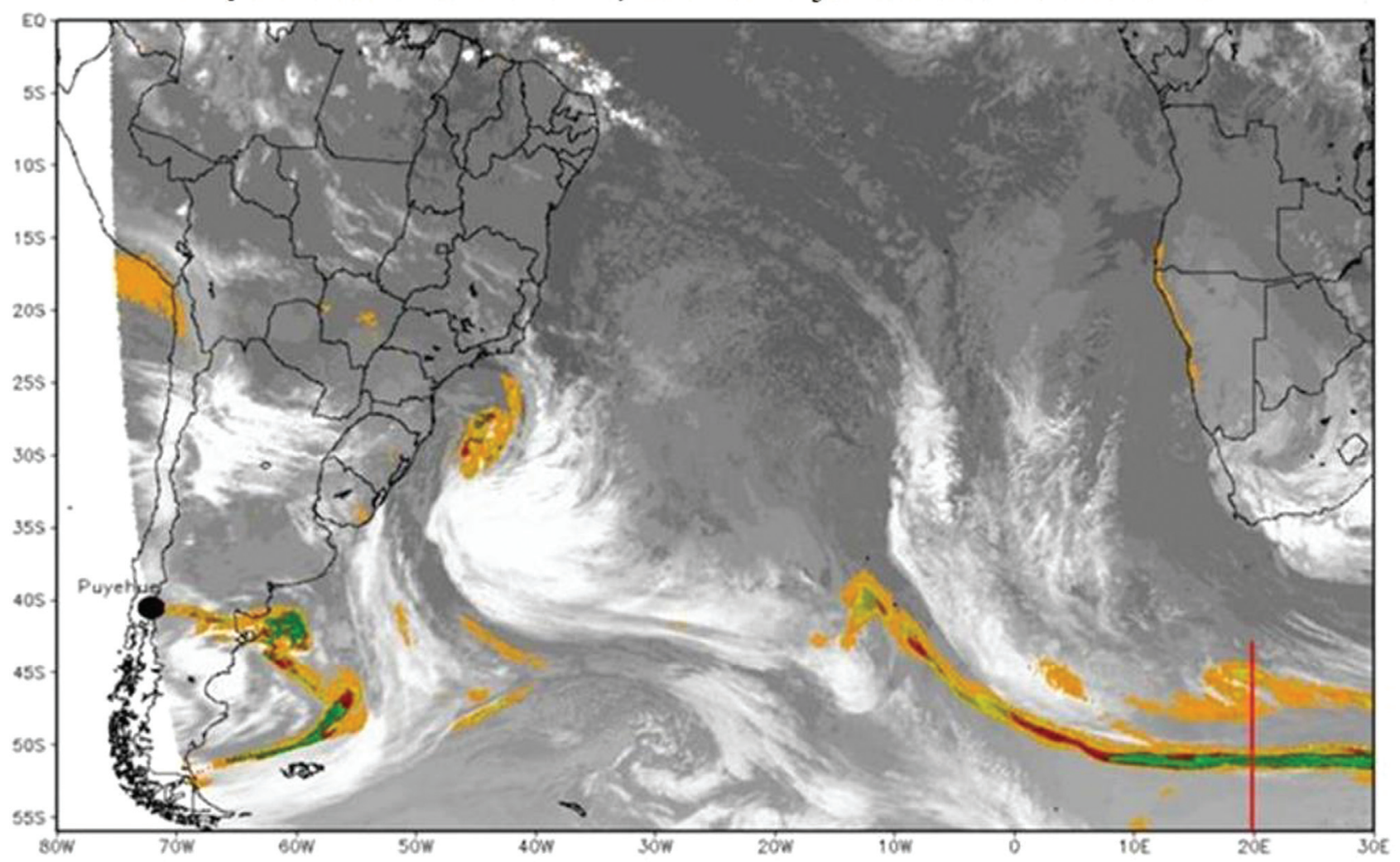

Figura 16 - Composição de IR10 em cinza e IR10-IR12 em cores, a cor verde significa que há forte sinal de presença de cinzas. Dia 08 junho de 2011 às 06Z. A linha vermelha indica onde foi analisado o perfil vertical de cinzas. Fonte DSA/CPTEC. 
Perfilvertical das cinzas vulcânicas sobre a longitude de $20^{\circ}$ leste.
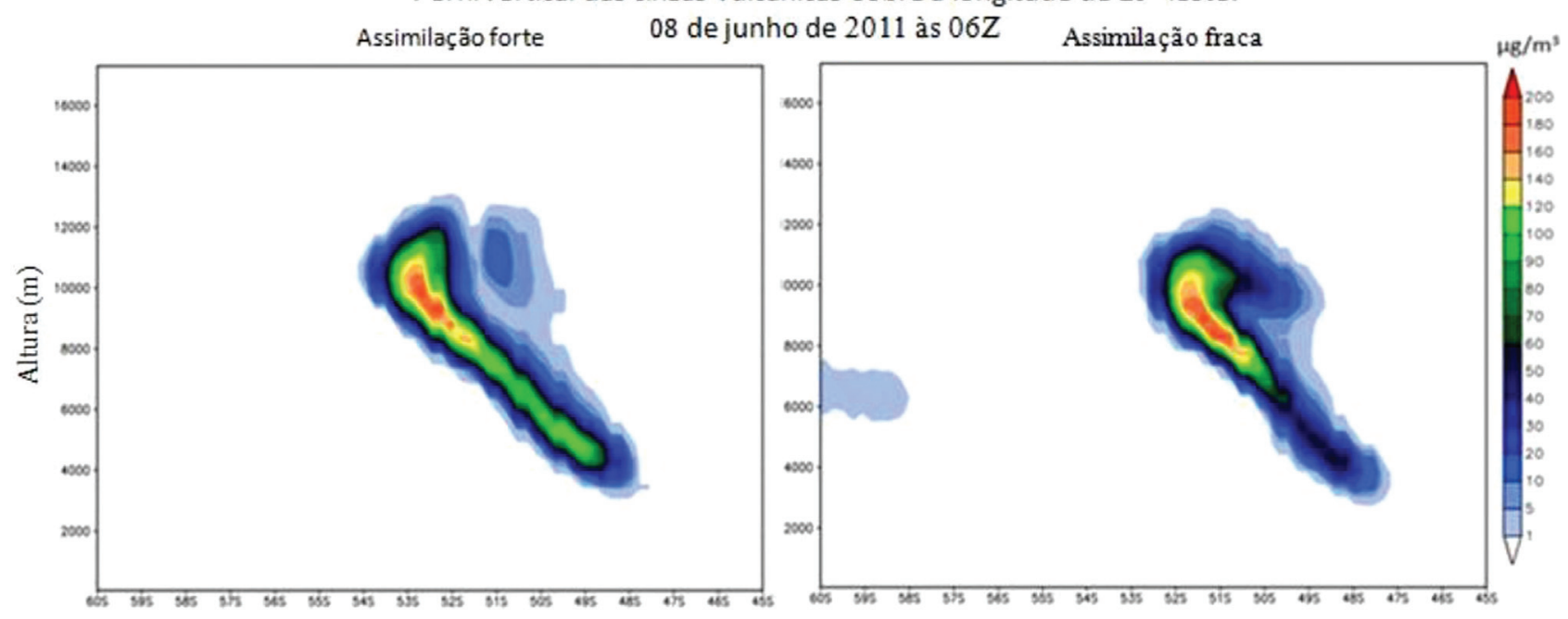

Figura 17 - Perfil vertical da concentração $\left(\mu \mathrm{g} / \mathrm{m}^{3}\right)$ das cinzas vulcânicas sobre a linha vermelha indicada na Fig. 16.

Diferença da concentração de cinzas vulcânicas sobre a longitude de $20^{\circ}$ leste.

05 de junho de 2011 às 06Z. (assimilação forte - assimilação fraca)

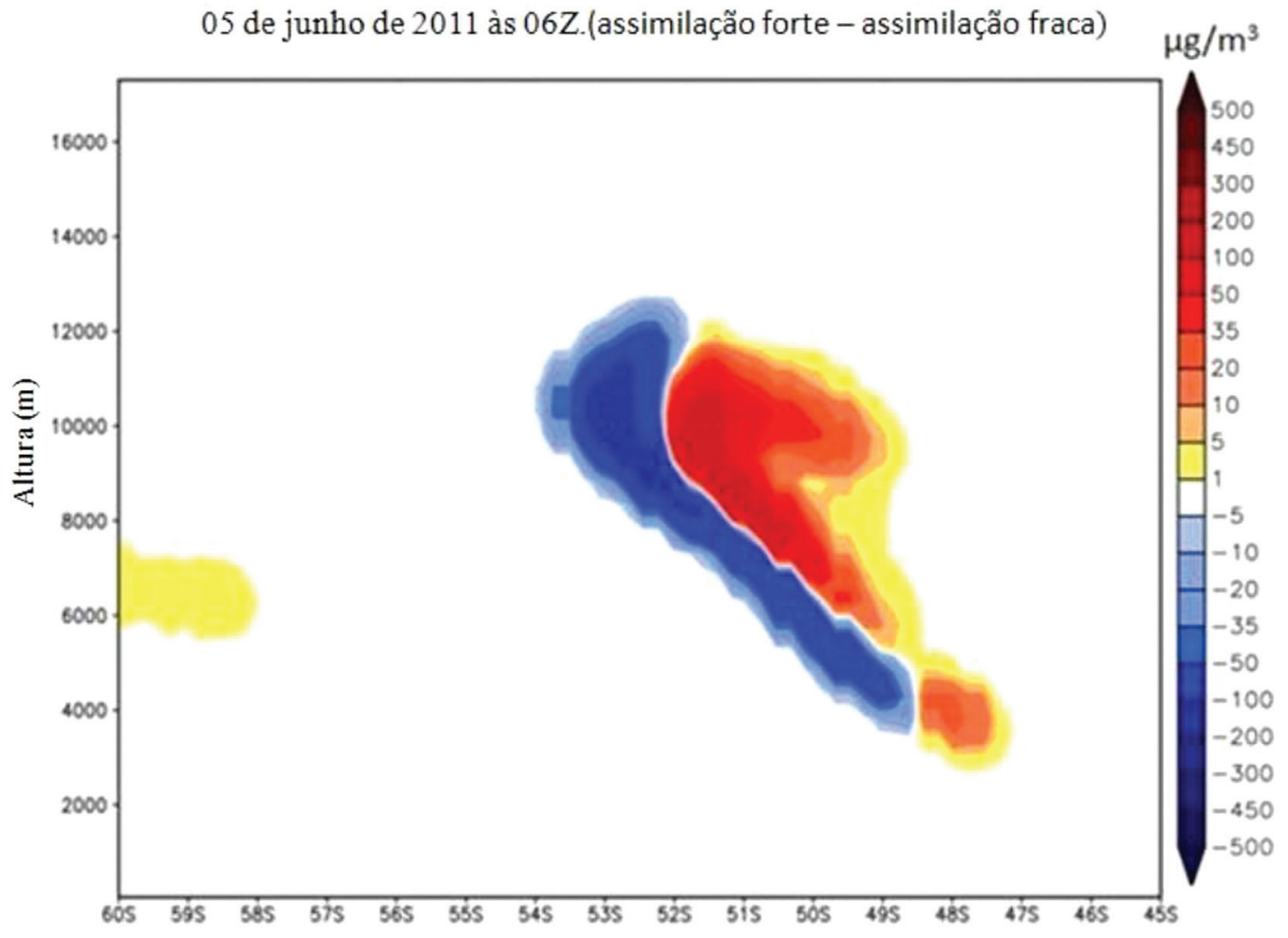

Figura 18 - Diferença do perfil vertical da concentração das cinzas vulcânicas $\left(\mu \mathrm{g} / \mathrm{m}^{3}\right)$ sobre a linha vermelha indicada na Fig. 16.

ponto de vista observacional, pois a pluma simulada fica mais próxima do campo observado.

No experimento de análise de sensibilidade em relação à condição de contorno, concluiu-se que, ao utilizar a condição de contorno "análise CPTEC" ao invés da "reanálise ERA" houve uma sutil melhora no resultado da simulação do modelo. Outra condição de contorno aplicada foi dada pelas previsões do modelo global do CPTEC, 'previsão CPTEC', este caso é relevante para estudar o comportamento do modelo em situações de tempo real e previsão futura, na qual somente as previsões do modelo global estarão disponíveis. Este caso foi comparado com a 
melhor condição de contorno obtida anteriormente, ou seja, utilizando somente análises do modelo global do CPTEC. Comparando estas duas condições de contorno com os dados observados, concluiu-se que ao utilizar a análise CPTEC a posição da pluma vulcânica fica mais próxima da posição da pluma indicada pelo produto de satélite. Mesmo assim, o resultado obtido com a condição de contorno dada pela previsão do CPTEC mostrou-se satisfatório o suficiente para afirmar que o modelo é capaz de prever a posição das cinzas vulcânicas com relativa acurácia.

Ao incluir a relaxação newtoniana no centro do domínio do modelo, concluiu-se que houve melhora significativa na posição da pluma. Porém, o aumento da intensidade da relaxação não implicou em melhoria significativa próximo à fonte emissora, mas produziu melhora em regiões distantes desta e em prazos mais longos.

Desta forma, depreende-se que a nova versão do modelo BRAMS, $5^{\text {a }}$ versão, possui elementos básicos para simular e prever a dispersão de cinzas vulcânicas e que, com os experimentos mostrados neste artigo, foi possível definir uma configuração do modelo apropriada para tal objetivo, sob o ponto de vista determinístico. Trabalhos futuros investigarão a aplicação de técnicas de previsão por conjunto, incluindo perturbações no campo inicial e de contorno atmosféricos, bem como nos parâmetros principais que caracterizam a emissão da pluma vulcânica, por exemplo a altura de injeção e distribuição de tamanho de cinzas. Desta forma, espera-se obter um produto de previsão mais robusto que melhor delimite as incertezas envolvidas numa previsão de longo prazo e distância. Um produto com estas características pode então ser implantado num centro operacional como o CPTEC/INPE atendendo demandas emergenciais associadas, por exemplo, ao tráfego aéreo da América do Sul. O custo computacional de um sistema como este é relativamente baixo por tratar de apenas 10 classes de aerossóis sem necessidade de incluir a solução de equações de microfísica de aerossóis e de reações químicas.

\section{Agradecimentos}

O primeiro autor agradece a CAPES que financiou o programa de mestrado e ao Ricardo Almeida de Siqueira que o acolheu no grupo GMAI. O segundo autor agradece ao CNPq (processo 3006340/2011-9). Os autores agradecem ao revisor anônimo que grandemente contribuiu para a melhoria da qualidade do manuscrito.

\section{Referências}

BARBARO, L.; KARLANIAN, M.; MAZZONI, A.; MORISIGUE D. Caracterización de las cenizas volcánicas del volcán Puyehue para su uso como sustrato In: CONGRESO ARGENTINO DE HORTICULTURA, Corrientes. Proceedings... Buenos Aires, AR. 2012. v. 35 p. 248, 2012.

BURSIK, M.I.; KOLBS, S. E.; BURNS, A.; BRAITSEVA, O. A.; BAZANOVA, L.I.; MELEKESTSEV, I.V.; KURBATOV,
A.; PIERI, D.C. Volcanic plumes and wind: Jetstream interaction examples and implications for air traffic. Journal of Volcanology and Geothermal Research, v. 186, p. 60-67, 2009.

COSTA, S.M.S.; LIMA, W.F.A.; FREITAS, S.R.; CEBALLOS, J.C.; RODRIGUES, J.V. Monitoramento dos Traços de Cinzas do Vulcão Chileno Puyehue -Cordón Caulle. In: CONGRESSO BRASILEIRO DE METEOROLOGIA, 17. (CBMET), Gramado. Anais... 2012. v. unico, p. 1-5. Papel, 2012. Disponível em: http://www.cbmet2012.com/trabalhos/. Acesso em: 04 abr. 2014.

DEVINISH, B.J.; FRANCIS, P.N.; JOHNSON B.T.; SPARKS, R.S.J.; THOMSON, D.J. Sensitivity analysis of dispersion modelling of volcanic ash from Eyjafjallajökull in May 2010. Journal of Geophysical Research, v. 117, p. 21, 2012.

FREITAS, S.R; RODRIGUES, L.F.; LONGO, K.M. Impact of a monotonic advection scheme with low numerical diffusion on transport modeling of emissions from biomass burning. Journal of Advances in Modeling Earth Systems, v. 4, p. M01001, 2012.

FREITAS, S.R.; LONGO, K.M.; RODRIGUES, L.F. Modelagem numérica da composição química da atmosfera e seus impactos no tempo, clima e qualidade do ar. Revista Brasileira de Meteorologia, v. 24, n. 2, p. 188-207, 2009a.

FREITAS, S.R.; LONGO, K.M.; SILVA DIAS, M.A.F.; CHATFIELD, R.; SILVA DIAS, P.; ARTAXO, P.; ANDREAE, M.O.; GRELL, G.; RODRIGUES, L.F.; FAZENDA, A.; PANETTA, J. The Coupled Aerosol and Tracer Transport model to the Brazilian developments on the Regional Atmospheric Modeling System (CATT-BRAMS) Part 1: Model description and evaluation. Atmospheric Chemistry and Physics, v. 9, p. 2843-2861, 2009b.

GRELL, G.; BAKLANOV, A. Integrated modeling for forecasting weather and air quality: A call for fully coupled approaches. Atmospheric Environment, v. 45, n. 38, p. $6845-685,2011$.

International Volcanic Health Hazard Network. Volcanic Gases and Aerosols Guidelines. Disponível em:http://www.ivhhn.org/images/pdf/gas_guidelines.pdf. Acesso em: 02 jan. 2012.

KRISTIANSEN, N.I.; STOHL, A.; PRATA, A.J.; BUKOWIECKI, N; DACRE, H.; ECKHARDT, S.; HENNE, S. HORT, M. C.; et al. Performance assessment of a vulcanic ash transport model mini-ensemble used for invirse modeling of the 2010 Eyjafjallajökull eruption. J. Geophysical Research, v. 117, p. D00U11, 2012, doi:10.1029/2011JD016844.

LIPMAN, P.W.; MULLINEAUX, D.R. The 1980 eruptions of Mount St. Helens. Washington: US Department of the Interior, US Geological Survey, 1982.

LONGO, K.M.; FREITAS, S.R.; PIRRE, M.; MARÉCAL, V.; RODRIGUES, L.F.; PANETTA, J.; ALONSO, M.F.; ROSÁRIO, N.E.; MOREIRA, D.S.; GÁCITA, M.S.; ARTETA J.; FONSECA, R.; STOCKLER, R.; KATSURAYAMA, D.M.; FAZENDA, A.; BELA, M. The Chemistry CATTBRAMS model (CCATT-BRAMS 4.5): a regional atmospheric model system for integrated air quality and weather forecasting and research. Geoscientific Model Development, v. 6, p. 1389-1405, 2013. 
MASTIN, L.G.; GUFFANTI, M.; SERVRANCKX, P.; WEBLEY, S.; BARSOTTI, K.; DEAN, A.; DURANT, J.W.; et al. A multidisciplinary effort to assign realistic source parameters to models of volcanic ash-cloud transport and dispersion during eruptions. Journal of Geophysical Research, v. 186, p. 10, 2009.

MENDONÇA, F.A.C. Cinzas Vulcânicas e a Segurança de voo. Conexão SIPAER, v. 3, p. 77-90, 2011.

National Aeronautics and Space Administration (NASA). Natural Hanzards. Disponível em: http://earthobservatory.nasa.gov/NaturalHazards Acesso em: 12 abr. 2012.

Observatório Volcanológico de los Andes del Sur (OVDAS). Actividad Volcánica 2010 y 2011 Región de Los Lagos. Disponível em: http://www2.sernageomin.cl/ovdas/ovdas7/informativos2/ RAV_X_2010.html. Acesso em: 16 de abril de 2012

PAVANI, C.A.B. Modelagem numérica do transporte de emissões vulcânicas: caso do vulcão Puyehue. 2014. 184 p. (sid.inpe.br/mtc-m18/2014/01.20.11.25-TDI). Dissertação (Mestrado em Meteorologia) - Instituto Nacional de Pesquisas Espaciais (INPE), São José dos Campos, 2014. Disponível

em: http://urlib.net/8JMKD3MGP8W/3FJUGQ8. Acesso em: 27 maio 2014.

PRUPPACHER, H.R.; KLETT, J.D. Microphysics of clouds and precipitation. 2. ed. Kluwer academic Publishers, Dordrecht, Netherlands, p. 954, 1997.

San Diego State University/The Department of Geological Sciences. How volcanoes work/Climate effects of volcanic eruptions. Disponível em: http://www.geology.sdsu.edu/how_volcanoes_work/climate_effects.html. Acesso em: 05 jan. 2012.

Smithsonian Institution (SI). Home. Disponível em: http://www.volcano.si.edu. Acesso em: 10 fev. 2012a.

Smithsonian Institution (SI). Puyehue-Cordón Caulle. Disponível em: http://www.volcano.si.edu/world/volcano.cfm?vnum $=1507-15=\&$ volpage=weekly\#Jul2011. Acesso em: 16 mar. 2012b
STUEFFER, M.; FREITAS, S.R.; GRELL, G.; WEBLEY, P.; PECKHAM, S.; MCKEEN, S.A.; EGAN, S.D. Inclusion of ash and SO2 emissions from volcanic eruptions in WRFChem: development and some applications, Geoscientific Model Development, v. 5, p. 2571-2597, 2012.

THE ATLANTIC. Chiles Puyehue volcano erupts. Disponível em:

http://www.theatlantic.com/infocus/2011/06/chiles-puyehu e-volcano-erupts/100081/. Acesso em: 15 fev. 2012.

U.S. Geological Survey (USGS). Ash properties \& dispersal by Wind. Disponível em: http://volcanoes.usgs.gov/ash/properties.html. Acesso em: 04 jan. 2012a.

U.S. Geological Survey (USGS). Health. Disponível em: http://volcanoes.usgs.gov/ash/health/index.html. Acesso em: 08 maio 2012 b.

U.S. Geological Survey (USGS). Volcanic ash: effects \& mitigations strategies, buildings. Disponível em: http://volcanoes.usgs.gov/ash/build/. Acesso em: 04 jan. 2015.

U.S. Geological Survey (USGS). Volcanic Gases and Climate Change Overview. Disponível em: http://volcanoes.usgs.gov/hazards/gas/climate.php. Acesso em: 14 maio 2014.

U.S. Geological Survey (USGS). Volcanic Gases and Their Effects Disponível em: http://volcanoes.usgs.gov/hazards/gas/index.php. Acesso em: 02 jan. 2012c

U.S. Geological Survey (USGS). Volcanic Sulfur Aerosols Affect Climate and the Earth's Ozone Layer. Disponível em: http://volcanoes.usgs.gov/hazards/gas/s02aerosols.php. Acesso em: 08 maio 2012d.

VUOLO, J. Introdução à Teoria de Erros. 3. ed. São Paulo: Universidade de São Paulo, 1999.

WEBSTER, H.N.; THOMSON, D.J.; JOHNSON, B.T.; HEARD, I.P.C.; TURNBULL, K.; MARENCO, N.I.; et al. Operational prediction of ash concentrations in the distal volcanic cloud from the 2010 Eyjafjallajökull eruption. Journal of Geophysical Research, v. 117, 2012, doi:10.1029/2011JD016790.

All the contents of this journal, except where otherwise noted, is licensed under a Creative Commons Attribution License CC-BY. 